\title{
Floral biology and pollination strategy of Durio (Malvaceae) in Sarawak, Malaysian Borneo
}

\author{
NG WIN SENG ${ }^{1}$, JAYASILAN MOHD-AZLAN ${ }^{1}$, WONG SIN YENG ${ }^{1,2, \boldsymbol{v}}$ \\ ${ }^{1}$ Institute of Biodiversity and Environmental Conservation, Universiti Malaysia Sarawak. 94300 Kota Samarahan, Sarawak, Malaysia. \\ ${ }^{2}$ Harvard University Herbaria. 22 Divinity Avenue, Cambridge, MA 02138, United States of America. `email: sywong@unimas.my.
}

Manuscript received: 25 September 2020. Revision accepted: 4 November 2020.

\begin{abstract}
Ng WS, Mohd-Azlan J, Wong SY. 2020. Floral biology and pollination strategy of Durio (Malvaceae) in Sarawak, Malaysian Borneo. Biodiversitas 21: 5579-5594. This study was carried out to investigate on the flowering mechanisms of four Durio species in Sarawak. The anthesis started in the afternoon (D. graveolens and D. zibethinus), evening (D. kutejensis) or midnight $(D$. griffithii); and lasted between 11.5 hours (D. griffithii) to 20 hours (D. graveolens). All four Durio species are generalists. Individuals of a fruit bat (Eonycteris spelaea, Pteropodidae) are considered as the main pollinator for D. graveolens, D. kutejensis, and D. zibethinus while spiderhunter (Arachnothera, Nectariniidae) is also proposed as a primary pollinator for D. kutejensis. Five invertebrate taxa were observed as secondary or inadvertent pollinators of Durio spp.: honeybee, Apis sp. (Apidae), stingless bee, Tetrigona sp. (Apidae), nocturnal wasp, Provespa sp. (Vespidae), pollen beetle (Nitidulidae), and thrip (Thysanoptera). Honey bees and stingless bees pollinated all four Durio species. Pollen beetles were found to pollinate D. griffithii and D. graveolens while nocturnal wasps were found to pollinate D. kutejensis and D. zibethinus. Thrips were found to pollinate $D$. griffithii only. Floral rewards include nectar, pollen and staminodes. The nectar production of D. graveolens, D. kutejensis, and D. zibethinus increased from the start of anthesis until just after midnight but decreased from then onwards. Durio griffithii produced consistent nectar concentration with inconsistent volume. Durio graveolens, $D$. griffithii, and $D$. zibethinus are partially self-incompatible.
\end{abstract}

Keywords: Dawn bat, floral visitors, fruit set, spiderhunter

\section{INTRODUCTION}

Durio Adans., a genus under the subfamily Helicteroideae Meisn. falls within the family of Malvaceae Juss. (Nyffeler and Baum 2001; Stevens 2020). The genus is separated into two subgenera: Boschia and Durio (Kostermans 1958; POWO 2019). However, Nyffeler and Baum (2001) supported the resurrection of Boschia as a genus based on the molecular evidence and the differences in the anther architecture. Durio s. lat. is distributed across tropical Southeastern Asia with Borneo as its center of diversity, 23 species (Kostermans 1958; Salma 2011; POWO 2019). Fifteen species are found in Sarawak: Durio acutifolius (Mast.) Kosterm., Durio affinis Becc., Durio carinatus Mast., Durio crassipes Kosterm. and Soegeng, Durio dulcis Becc., Durio excelsus Bakh., Durio grandiflorus (Mast.) Kosterm. and Soegeng, Durio graveolens Becc., Durio griffithii (Mast.) Bakh., Durio kutejensis Becc., Durio lanceolatus Mast., Durio oblongus Mast., Durio oxleyanus Griff., Durio testudinarius Becc., and Durio zibethinus L. (Kostermans 1958; Salma 2011; POWO 2019).

Durio s. lat. can be distinguished by the surface of the branchlets clothed with small scales and the lower surface of the leaf lamina covered with stellate hairs and topped by a layer of coppery brown scales (not always). The inflorescences are borne on young branchlets, on older branches or on the bole, sometimes at the base of the bole, consisting of few-flowered cymes on reduced and hardly branched or unbranched peduncles. The flowers are small to large, covered by lepidote bracts and each comprises of an epicalyx and calyx. The calyx splits into five free sepals (not always) with the petals in (4-) 5 (-6), and the stamens are numerous, either free or united in five phalanges, or a combination of two with the anthers are unilocular, either opening by a longitudinal slit (subgenus Durio) or by an apical pore (subgenus Boschia). The fruits are capsular, globular to ellipsoid, often sulcate, usually 5-locular with the valves are either dehiscent or indehiscent with the seeds are usually arillate (Kostermans 1958; Nyffeler and Baum 2001). The commercial value of Durian has gone beyond just direct consumption. Durian rinds, for example, have great potential to be processed as non-wood based raw material for the pulp and paper industry (Masrol et al. 2015). The seeds can be extracted to produce hydrocolloid which can be used as dietary fiber, food thickeners, and packaging films (Amid and Mirhosseini, 2011), a new substrate substitute for the production of angkak, a type of fermented rice used to color and preserve foods and beverages in Southeast Asia (Srianta et al. 2012), and production of vegan mayonnaise by replacing egg yolk during production (Cornelia et al. 2015).

The degree of self-incompatibility varies among several species studied in the genus. Many clones/cultivars/ varieties of $D$. zibethinus were found to be leaning towards self-incompatible spectrum (Lim and Luders 1998; Bumrungsri et al. 2009). However, Jutamanee and Sirisuntornlak (2017) reported no self-incompatible 
phenomenon in 'Monthong' variety of D. zibethinus, selfpollination within the same tree produced higher fruit set than open-pollination. Yumoto (2000) reported that $D$. grandiflorus, D. oblongus, and D. kutejensis are obligate outbreeders although these species are self-incompatible.

Most pollination studies of Durio were directed at investigations of the interactions between bats and their host Durio plants (Sheema et al. 2017; Chaiyarat et al. 2019). While without doubt, many Durio species are pollinated by bats, recent studies revealed that most species are in fact also pollinated by spiderhunters and insects (Yumoto 2000; Wayo et al. 2018). Investigations of the cultivated durian, D. zibethinus were largely carried out in Peninsular Malaysia and Thailand (Soepadmo and Eow 1977; Bumrungsri et al. 2009; Sheema et al. 2017; Wayo et al. 2018; Chaiyarat et al. 2019). For Sarawak, the floral biology and pollination mechanisms of $D$. grandiflorus, $D$. kutejensis, and D. oblongus were studied in a natural forest setting at Lambir National Park (Yumoto 2000). Durio kutejensis was found to be pollinated by bats and also by honey bees and birds, while $D$. grandiflorus and $D$. oblongus were reported to be pollinated by spiderhunters (Nectariniidae) (Yumoto 2000). Durio kutejensis and D. graveolens are two of several native species that are popular for their fruits. It so coincided that we found a mixed fruit orchard in Limbang with the presence of three Durio species, D. graveolens, D. kutejensis, and D. zibethinus cultivated for commercial purposes. In addition, we also have access to $D$. griffithii in Mulu National Park, which belongs to subgenus Boschia. Thus, this study aimed to expand and include investigations on the floral biology and pollination mechanism of four Durio species (D. graveolens, D. griffithii, D. kutejensis, and D. zibethinus) in Sarawak.

\section{MATERIALS AND METHODS}

\section{Plant species and study sites}

Four species were selected for this study, namely, $D$. griffithii, D. graveolens, D. kutejensis, and D. zibethinus. The observations of $D$. griffithii were carried out in a primary lowland alluvial forest at Mulu National Park, Miri from 9 June 2019 to 12 October 2019 (Figure 1). Durio griffithii was located near the park headquarter and along the trail to Deer Cave (ca. $04^{\circ} 020 \mathrm{~N}, 114^{\circ} 490 \mathrm{E}, 39 \mathrm{~m}$ elev.). The observations of $D$. graveolens, D. kutejensis, and $D$. zibethinus were conducted at a mixed fruit orchard in Limbang (ca. $4^{\circ} 02^{\prime} 31.85^{\prime}$ "N 11448’45.10” E, $16 \mathrm{~m}$ elev.) from 12 September 2018 to 7 June 2019 (Figure 1). The fruit orchard is surrounded by fragments of natural forest and most of the Durio spp. were planted between 20 to 70 years ago. Fruit orchards have been considered as one of the models of secondary forest area utilization by empowering the local community members to cultivate the forest gardens with plants such as durian (D. zibethinus) and other fruit or timber trees (Apuy et al. 2017; Winarni et al. 2017; Matius et al. 2018).

The detailed morphological differences of the reproductive structures of each species are provided below, following Kostermans (1958).

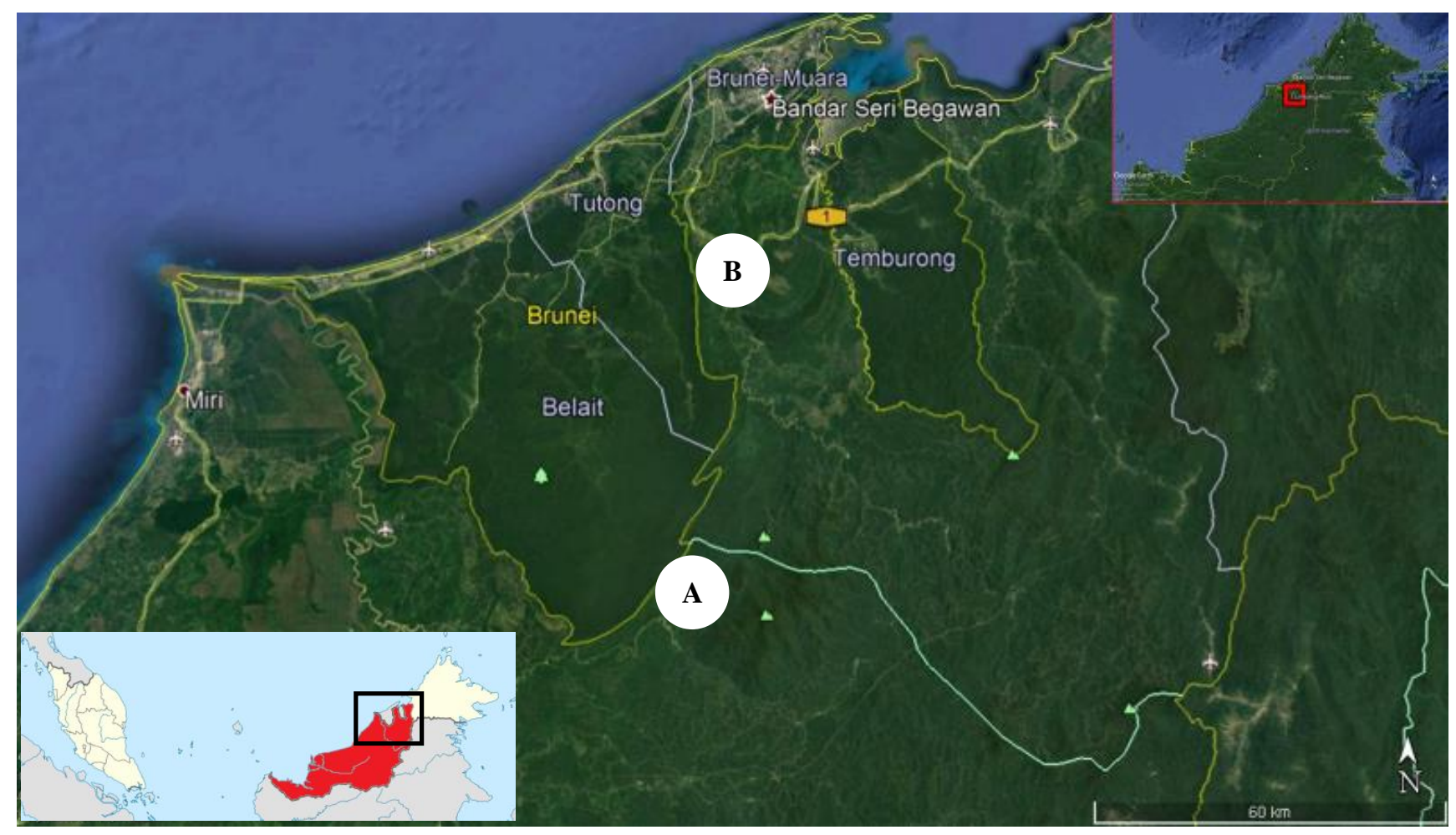

Figure 1. Map of the sampling localities. A. Mulu National Park, B. A mixed fruit orchard in Limbang. Map on the top right shows the localities on Borneo (Google Earth 2020). 
The flowers of $D$. griffithii are small, solitary, or in a two-three flowered cyme, emerging axillary (Figure 2). The calyx is separated into four greenish-white sepals which are lanceolate, acute, and spreading. The petals are 4-8, linear, or linear-spathulate, glabrous, yellowish-white or green-white, turning orange after anthesis, spreading, or reflexed. All staminodes are free with a small ovoid, sterile anther at apex. The stamens are as many and as long as the staminodes; each with up to 6 obovoid, poro-dehiscent anthers. The fruits are scarlet when fresh, ellipsoid-obovoid with the base and top acute; dehiscent into two to three valves on the branch. Seeds are glossy black with a thin orange or red aril, enveloping only the basal part of the seeds (Kostermans 1958).

The inflorescences $D$. graveolens are in a two, three, or more flowered (rarely flower solitary) cyme on old branchlets or on older branches (Figure 3). The petals are in five, broadly spathulate-rotundate, white, erect, and later reflexed. The stamens and staminodes are in five which are white, glabrous, and erect. The anthers are reniform, about three on each filament, brown, and dehiscent with slits. The fruits are orange-yellow, globose, or somewhat ellipsoid with sharp pyramidal, ochroid, $1 \mathrm{~cm}$ long spines. The fruits are dehiscent into five valves while on the branches. The seeds are glossy brown and completely enclosed by an edible, fleshy, and color ranging from yellow to dark red aril (Kostermans 1958; Kurniadinata et al. 2020).
The flowers of D. kutejensis are in three or moreflowered, irregular racemes on older branches (Figure 4). The calyx is cup-shaped and five-toothed. The petals are in five, spathulate or broadly spathulate, inside glossy, beefyred, and glabrous. The filaments are red, numerous, all free with the anthers white, reniform, dehiscent with a slit, 10 or more on each filament. The fruits are dirty yellow, ovoid or ellipsoid, pentangular with often somewhat curved spines (1-1.5 cm long); the spines are soft and covered with a layer of minute stellate hairs, topped by scattered scales. The fruit drops unopened. The seeds are ellipsoid, glossy brown, completely enclosed by a fleshy, yellow, nice smelling, and palatable aril (Kostermans 1958; Handayani 2016; Santoso 2010; Handayani and Rahayu 2017; Tirtawinata and Mulyanto 2017).

The inflorescences of $D$. zibethinus are borne on older branches, forming fascicles of corymbs of 3-30 flowers (Figure 5). The calyx is tubular or urceolate, saccate, and flattened at base with 5-6 teeth. The petals are white, convolute in their upper part, about twice as long as the calyx, spathulate-cochleate, rounded at apex. The stamens are in five free phalanges; each filament with up to 12 reniform anthers, dehiscent by a slit. The fruit drops unopened and is green to yellow, globose, ovoid or ellipsoid with the spines broadly pyramidal and sharp. The seeds are completely covered by a white or yellowish, soft, and very sweet aril (Kostermans 1958; Syahruddin 2012; Indriyani et al. 2012; Hariyati et al. 2013).
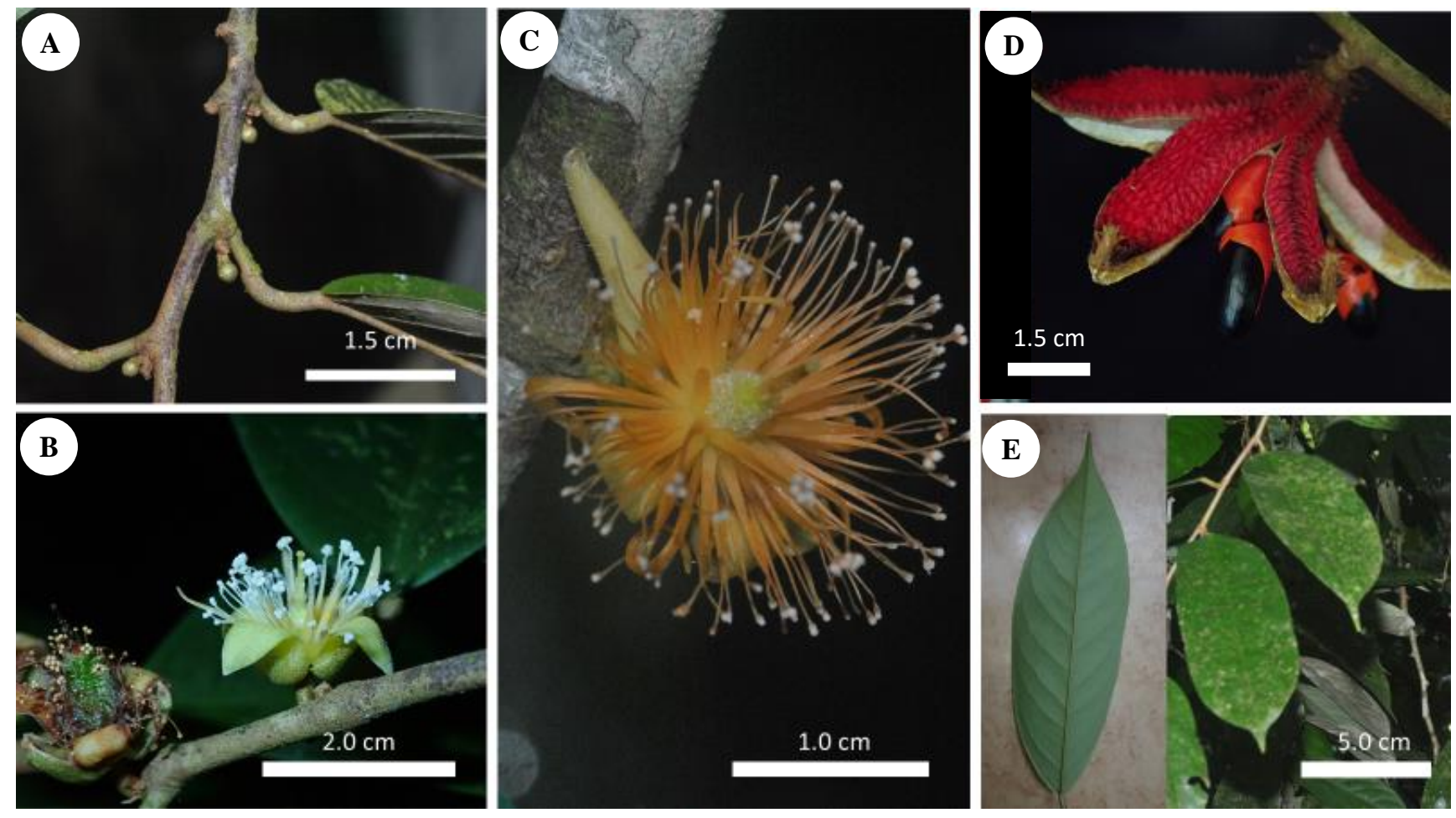

Figure 2. Durio griffithii. Vegetative and reproductive structures. A. Floral buds appear on leaf axils. B. Flower at the first day of anthesis (right), young fruit seven days after anthesis (left). C. Flower at post-anthetic stage. D. Mature fruit, dehiscent on tree. E. Leaf blade, abaxial surface (left), adaxial surface (right). Photographs by Ng WS 


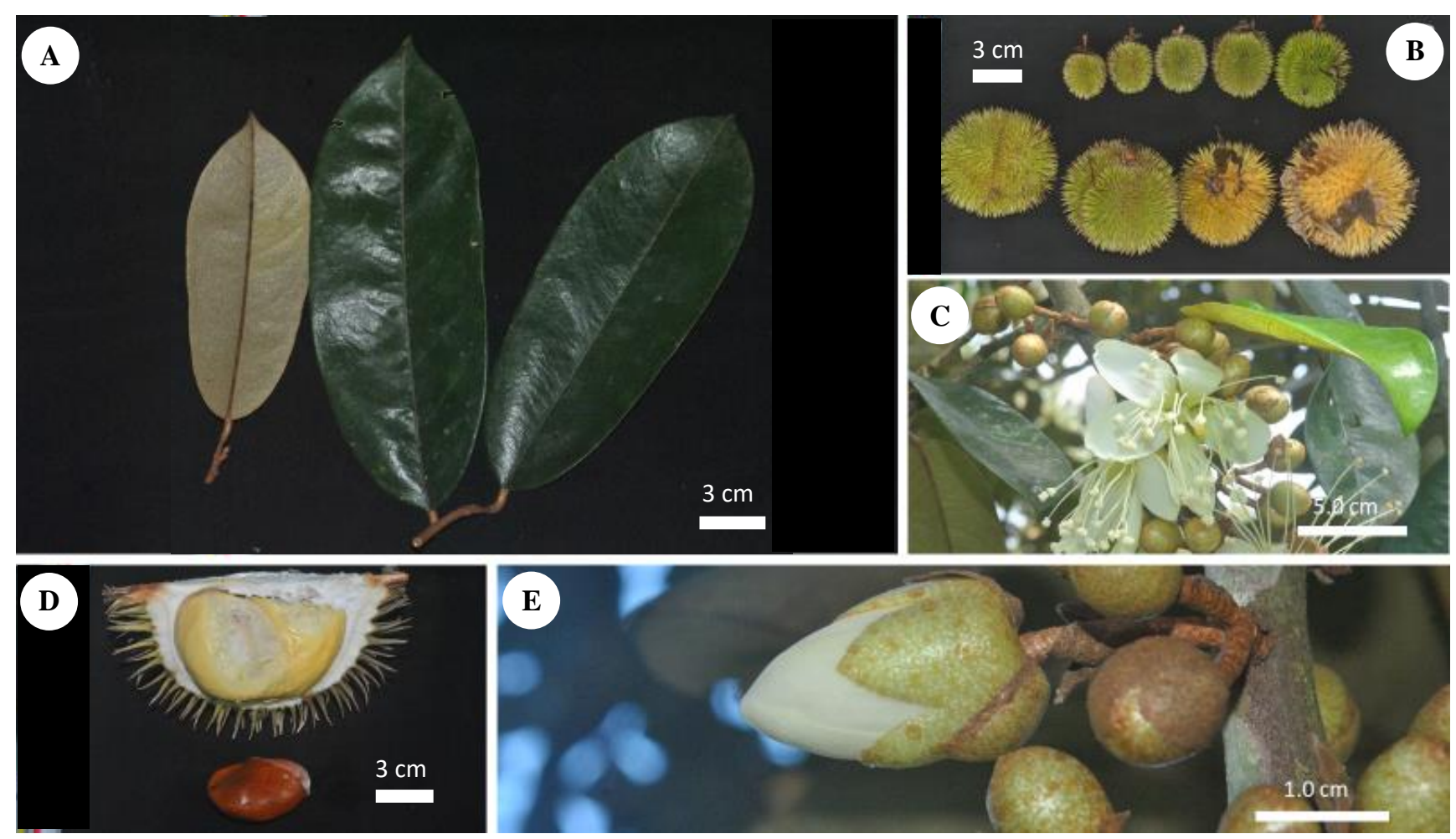

Figure 3. Durio graveolens. Vegetative and reproductive structures. A. Leaf blade, abaxial surface (left), adaxial surface (right). B. Fruits in various stages of growth from left to right, top to bottom. C. Flowers at the beginning of female anthesis surrounded by floral buds (1-2 days before anthetic stage). D. Dissected mature fruit on top and seed below. E. Flower bud two hours before female anthesis. Photographs by Ng WS
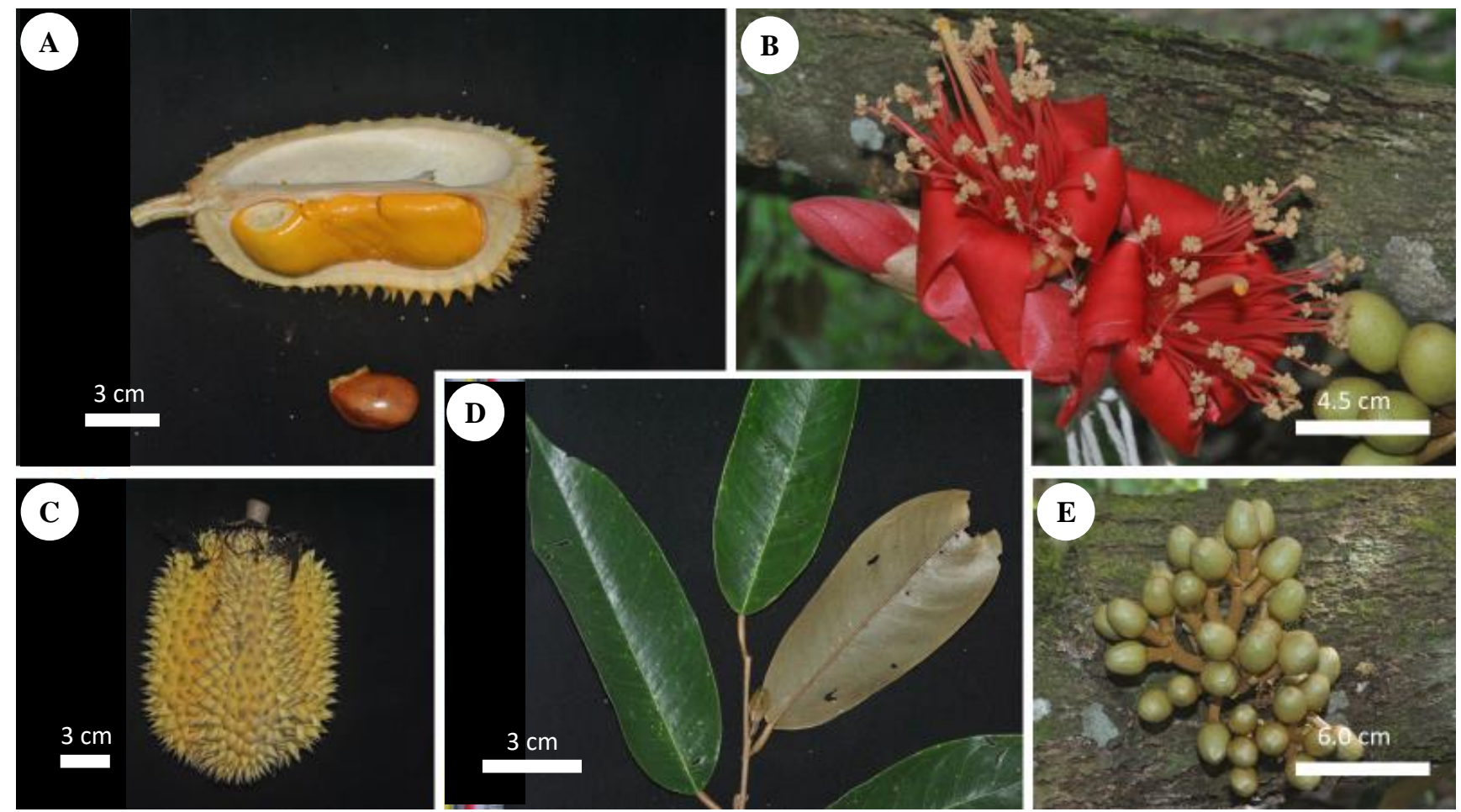

Figure 3. Durio kutejensis. Vegetative and reproductive structures. A. Dissected mature fruit on top and seed below. B. Floral bud c. 10 hours before blooming (left), flower at the end of female anthesis on day 2 (centre), flower buds c. 2 weeks before anthesis (right). C. Mature whole fruit. D. Leaf blade, adaxial surface (left), abaxial surface (right). E. Flower buds in early stage of growth. Photographs by $\mathrm{Ng}$ WS 

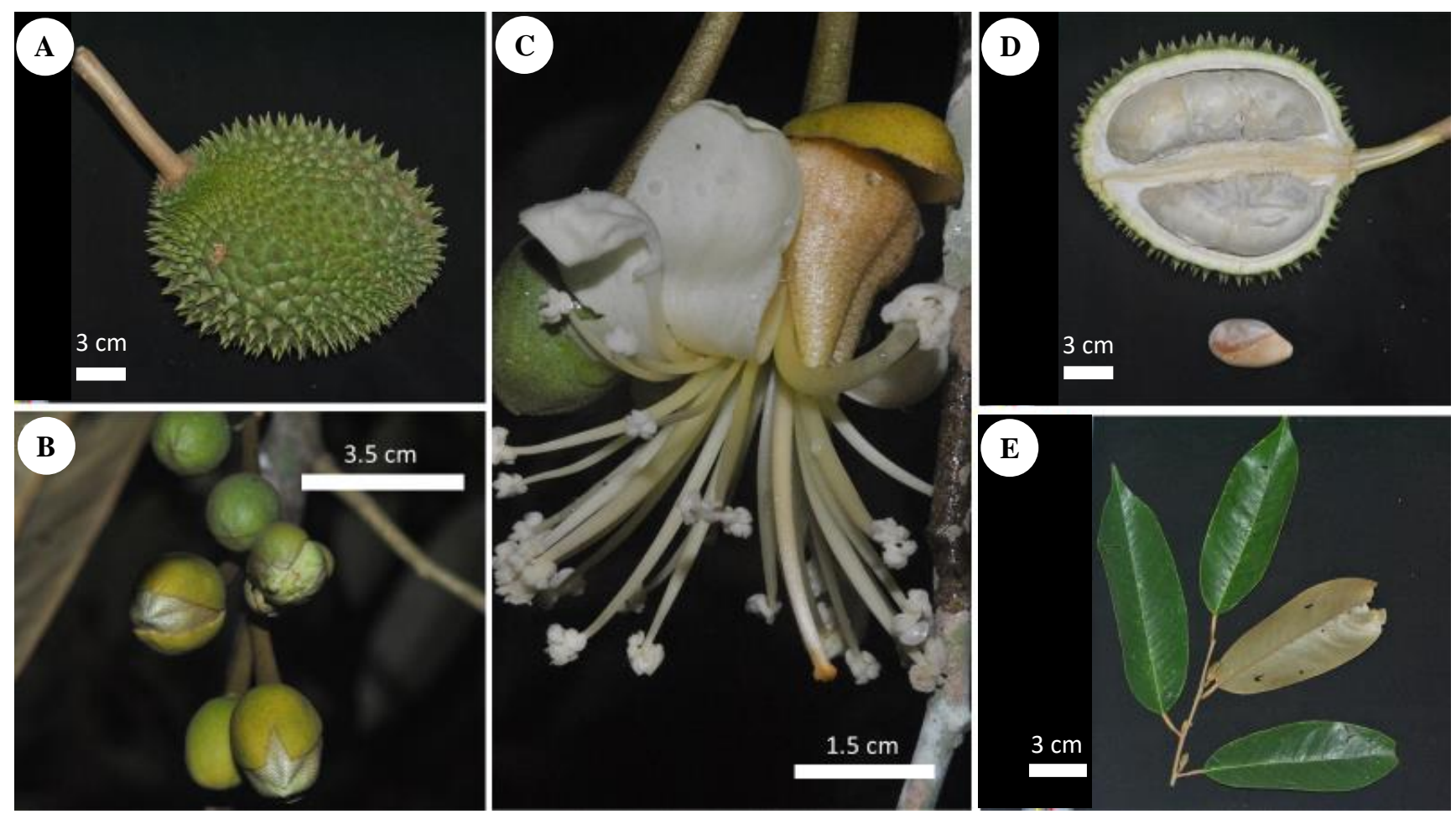

Figure 4. Durio zibethinus. Vegetative and reproductive structures. A. Mature whole fruit. B. Floral buds with epicalyx split revealing the calyx. C. Flower in full bloom at the start of female anthesis. D. Dissected mature fruit on top and seed below. E. Leaf blade, adaxial surface (left), abaxial surface (right). Photographs by Ng WS.

\section{Floral biology and visitors}

Inflorescences of the investigated taxa were identified and observed at least a week prior to anthesis. Observations on the flowering mechanisms were carried out on a one hour to three hours interval from the start until the end of anthesis with direct observation, a binocular and/or a torchlight (for night observation). The stigmatic receptivity was assessed using $3 \%$ hydrogen peroxide $\left(\mathrm{H}_{2} \mathrm{O}_{2}\right)$ solution, in which the formation of gas bubbles is indicative of peroxidase enzyme activity (Dafni 1992). The stigmatic receptivity was noted to be associated with visible changes in the presence of stigmatic exudate, providing a logistically easier indicator of receptivity. The onset of the staminate phase was indicated by pollen release. The phases of anthesis and the events of floral movement, floral scent emission, pollen extrusion and nectar production were recorded. The odor gland position was determined by placing the different floral parts into clean and odorless vials. Several flowers from each species were used when odor strength is weak. The vials were smelled to determine the location of the osmophores (Dafni 1992). Throughout the entire duration of anthesis, the behavior of insect visitors was also documented. The average number of floral visitors per hour were recorded. The assessment to determine if the floral visitors were effective pollinators was made based on the following criteria: relative visitation rate; coincidence of visits with the duration of the pistillate and staminate floral phases; and attachment of pollen grains to the floral visitor (if possible).
Inflorescences and infructescence of each species were randomly selected from different trees (Table 1). Photographs were taken using camera model Nikon D3000 for $D$. kutejensis, D. graveolens, and D. zibethinus while compact camera model Olympus TG-5 was used for $D$. griffithii. All inflorescences and insect visitors were preserved in 70\% ethanol and deposited at the Sarawak Forestry Herbarium (SAR) and Sarawak Forestry Entomology Museum. Voucher information for all taxa is provided in Table S1. Identifications of the anthophilous insects to the lowest possible taxonomic level were conducted by the authors.

\section{Floral differentiation}

Several inflorescences each bearing several buds were randomly sampled and tagged. Floral buds at various growth stages were selected, starting from bud extrusion until to just before anthesis. The developing buds were cut longitudinally to expose the epicalyx, calyx, petals, stamens, and pistils, and photographed. In addition, the length of the stamens and pistil of mature floral buds were measured twice (the day before anthesis and onset of anthesis). The growth period from bud initiation to anthesis was recorded at 7-8 days interval for $D$. graveolens, $D$. zibethinus, and D. kutejensis while D. griffithii was recorded at a 2-3 days interval. The measurements were taken 3-7 days after bud extrusion as the initial floral buds were too fragile. The diameter and length of the bud were measured with a digital vernier caliper. The number of replicates and dates of data collection are provided in Table 1. 
Table 1. The number of replicates and date of observations or experiments

\begin{tabular}{|c|c|c|c|c|}
\hline & D. griffithii & D. graveolens & D. kutejensis & D. zibethinus \\
\hline \multirow[t]{2}{*}{ Floral biology } & $29 / 3 / 4^{*}$ & $36 / 4 / 18^{*}$ & $38 / 3 / 4 *$ & $41 / 4 / 20^{*}$ \\
\hline & 8 Jun. 2019-19 Nov. 2019 & 16 Sept. 2018-8 Nov. 2018 & 14 Sept. 2018- 15 Dec. 2018 & 15 Sept. 2018-8 Nov. 2018 \\
\hline Floral & $34 / 3 * *$ & $38 / 4 * *$ & $46 / 3^{* *}$ & $43 / 4 * *$ \\
\hline differentiation & 9 Sept. 2019-26 Sept. 2019 & 4 Apr. 2019-28 May 2019 & 23 Mar. 2019- 2 Jun. 2019 & 8 Apr. 2019- 17 May 2019 \\
\hline Nectar & $81 / 3 * *$ & $76 / 4 * *$ & $73 / 3 * *$ & $67 / 4 * *$ \\
\hline production & 2 Sept. 2019-27 Sept. 2019 & 10 May 2019- 24 May 2019 & 10 Apr. 2019- 14 May 2019 & 25 Apr. 2019- 13 May 2019 \\
\hline Pollination & $\mathrm{T} 141 / 3^{* *}$ & $\mathrm{~T} 135 / 4 * *$ & -- & $\mathrm{T} 133 / 4 * *$ \\
\hline \multirow{4}{*}{ experiments } & $\mathrm{T} 2$ 42/3** & $\mathrm{T} 231 / 4 * *$ & & $\mathrm{~T} 232 / 4 * *$ \\
\hline & T3 41/3** & T3 33/4** & & T3 34/4** \\
\hline & $\mathrm{T} 443 / 3 * *$ & $\mathrm{~T} 434 / 4 * *$ & & $\mathrm{~T} 430 / 4 * *$ \\
\hline & 26 Sept. $2019-9$ Oct. 2019 & 21 Apr. 2019- 27 May 2019 & & 23 Sept. 2019-2 Nov. 2019 \\
\hline
\end{tabular}

Note: T1: Treatment 1 (bagged flowers); T2: Treatment 2 (open pollination); T3: Treatment 3 (manually cross pollination); T4: Treatment 4 (self-pollination). * number of inflorescences/ number of trees involved/number of trees in the population. ** number of inflorescences/ number of trees involved

Table S1. List of sampled taxa vouchers, localities, and accession numbers included in this study

\begin{tabular}{ll}
\hline Taxon & Voucher \\
\hline $\begin{array}{l}\text { Durio graveolens } \\
\text { Durio graveolens }\end{array}$ & MALAYSIA: Sarawak, Limbang, Ukong, 14 January 2019, Ng Win Seng DUR25 (SAR) \\
Durio graveolens & MALAYSIA: Sarawak, Limbang, Ukong, 14 January 2019, Ng Win Seng DUR26 (SAR) \\
Durio griffithii & MALAYSIA: Sarawak, Miri, Mulu N.P., 9 Dec 2018, Wong Sin Yeng \& P. C. Boyce, DUR18 (SAR) \\
Durio griffithii & MALAYSIA: Sarawa,, Miri, Mulu N.P., 19 Jun 2019, Ng Win Seng, DUR40 (SAR) \\
Durio griffithii & MALAYSIA: Sarawak, Miri, Mulu N.P., 21 Sept 2019, Ng Win Seng, DUR44 (SAR) \\
Durio zibethinus & MALAYSIA: Sarawak, Kuching, Matang, Kubah N.P., 23 June 2018, Wong Sin Yeng \& P. C. Boyce DUR3 (SAR) \\
Durio zibethinus & MALAYSIA: Sabah, Lahad Datu, Danum Valley, 5 Jul 2018, Wong Sin Yeng \& P. C. Boyce DUR4 (SAR) \\
Durio zibethinus & MALAYSIA: Sarawak, Kuching, Matang, Kubah N.P., 6 October 2018, Wong Sin Yeng \& P. C. Boyce DUR10 (SAR) \\
Durio zibethinus & MALAYSIA: Sarawak, Miri, Mulu N.P., 15 Nov 2018, Chai Shong Kian DUR12 (SAR) \\
Durio zibethinus & MALAYSIA: Sarawak, Miri, Mulu N.P., 9 Dec 2018, Wong Sin Yeng \& P. C. Boyce, DUR17 (SAR) \\
Durio zibethinus & MALAYSIA: Sarawak, Limbang, Ukong, 14 January 2019, Ng Win Seng DUR23 (SAR) \\
Durio zibethinus & MALAYSIA: Sarawak, Limbang, Ukong, 14 January 2019, Ng Win Seng DUR24 (SAR) \\
Durio zibethinus & MALAYSIA: Sarawak, Kuching, Matang, Kubah N.P., 13 March 2019, Ng Win Seng DUR33 (SAR) \\
Durio zibethinus & MALAYSIA: Sarawak, Miri, Mulu N.P., 12 Jun 2019, Ng Win Seng, DUR36 (SAR) \\
Durio zibethinus & MALAYSIA: Sarawak, Miri, Mulu N.P., 12 Jun 2019, Ng Win Seng, DUR37 (SAR) \\
Durio zibethinus & MALAYSIA: Sarawak, Miri, Mulu N.P., 19 Jun 2019, Ng Win Seng, DUR39 (SAR)
\end{tabular}

\section{Nectar production}

The nectar sampling was collected by using injection syringe $(5 \mathrm{~mL}, 3 \mathrm{~mL}$ and $10 \mu \mathrm{L})$ just after flower opening, and thereafter at intervals of $2 \mathrm{~h}$ over $24 \mathrm{~h}$, depending on the available number of flowers with each sampling was conducted on different flowers. The flowers were not bagged, thus permitting unhindered animal visitation. The sugar concentration was estimated by a refractometer (RHB-32, Westover Scientific, US) as sucrose equivalent. The number of replicates and date of samplings is shown in Table 1. As the datasets were normally distributed, analysis of variance (ANOVA) tests was applied. All statistical tests were carried out using Paleontological Statistics (PAST) version 2.17 (Hammer et al. 2001).

\section{Pollination experiments}

To examine the breeding system of Durio species ( $D$. griffithii, D. graveolens, and D. zibethinus), four experiments were performed: Treatment 1 (T1)-untreated, flowers were bagged before each flower bloomed; Treatment 2 (T2)-open flowers were left exposed permitting unhindered animal visitation; Treatment 3 (T3)-cross-pollination flowers were bagged before each flower bloomed and were hand-pollinated with pollen from the flowers of a different tree collected just before the hand-pollination; Treatment 4 (T4)-self-pollinated (geitonogamous) flowers were bagged before each flower bloomed and were hand-pollinated with geitonogamous pollen from different flowers on the same tree collected just before the hand-pollination. Pollination experiment was not performed on D. kutejensis because the population 
had not been observed to set fruit in the past. The flowers were bagged by non-woven bags. In hand-pollination, pollen was transferred using brushes. The flowers were checked three days and ten days after the anthesis. The pollination treatments were considered successful if the gynoecium remained intact on the third day after anthesis. The fruit set was determined again at 10 days after anthesis as high failure rate was observed. Details on the dates and replicates of the pollination experiments are listed in Table 1.

An index was employed to describe the breeding systems; an index of self-incompatibility (ISI) was calculated by dividing the average number of hand-selfed seed set per flower by hand cross-pollination seed set, values above score 1 are self-incompatible, score less than and between 1 and 0.2 are partially self-incompatible, score less than 0.2 are mostly self-incompatible and score 0 are completely self-incompatible (Zapata and Arroyo 1978). A ranking of automatic self-pollination was obtained for selfcompatible species by comparing percentage of fruit set following controlled selfing (Dafni 1992). Fully autogamous plants, 0-3\% fruit set, were ranked as Class 0 , while partially autogamous plants, 3-30\% were ranked as Class 1. Self-compatible species with selfing score higher than $30 \%$ were ranked as Class 2 .

\section{RESULTS AND DISCUSSION}

\section{Floral differentiation}

The floral development of all four observed species was similar at their initial phase. At bud break, the buds appeared as small protuberances with the scales enclosing numerous floral primordia. Initially, the equatorial and polar diameter increased proportionately, but the polar diameter increased more rapidly than the equatorial diameter (Figure 6), such that the bud shape changed from a sphere to an ellipsoid structure (Figure 7). The stamens coiled in D. graveolens, D. kutejensis, and D. zibethinus but not in D. griffithii during bud stage as the length of the stamens exceeded the height of the cavity within the bud. The coiling of the stamens generated pressure which later assisted in pushing the petals out during blooming. Three days to a day before anthesis, the epicalyx split to expose the calyx. During anthesis, the stamens and pistil doubled in size. The duration needed from bud break to blooming took two to three weeks in D. griffithii, six to seven weeks in D. graveolens, eight to nine weeks in D. kutejensis, and seven to eight weeks in $D$. zibethinus.
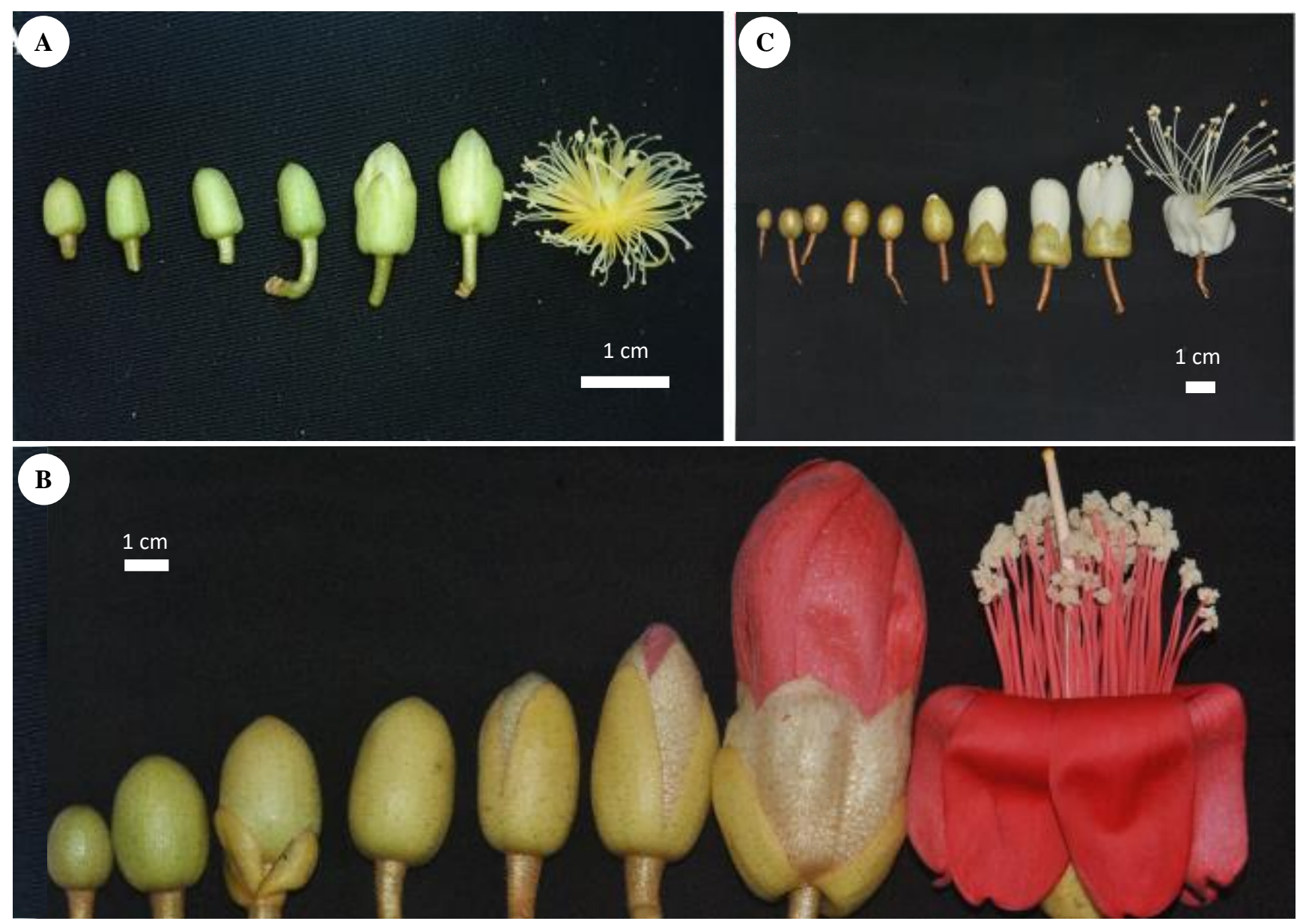

Figure 5. The growth of floral buds from bud initiation to flowering. A. Durio. griffithii, B. D. graveolens, C. D. Kutejensis 

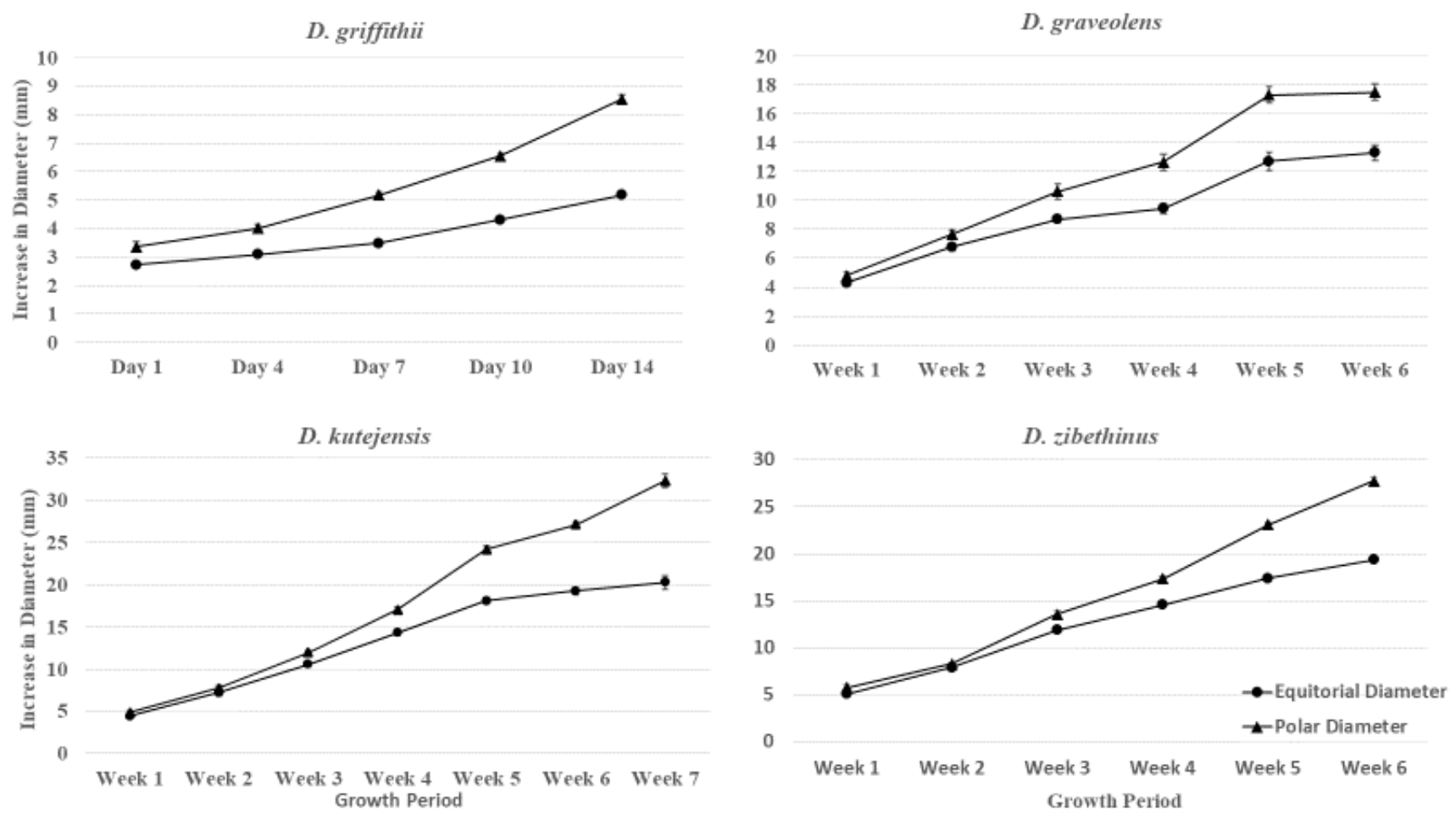

Figure 6. The changes in equatorial and polar diameter of floral bud of four species, standard error is represented by the vertical bars

\section{Flowering phenology}

Inflorescences of D. griffithii were found throughout the year (second author, pers. observ.). Flowering events of D. graveolens, D. kutejensis, and D. zibethinus peaked between July-October, September-October, and JulyOctober respectively. All three Durio species were found to start flowering as early as April. For all four Durio species, only one flower per inflorescence bloomed at any given time. For D. graveolens, D. kutejensis, and D. zibethinus, the next flower of the same inflorescence opened by the next day but delayed in $D$. griffithii, two to four days. For $D$. graveolens, D. kutejensis, and D. zibethinus, a delay of two to five days between flowering events were also observed. Overlapping of flowering events within the same inflorescence was not observed.

\section{Flowering habit}

Three days before anthesis, c. 09:00 pm, the epicalyx of D. griffithii split to expose the calyx (Figure 8). The calyx began to split at $11: 30 \mathrm{pm}$, the night before anthesis to reveal the petals, stamens, staminodes, and pistils. The flowers of D. griffithii opened at 01:30 am (Day 1) and the floral odor was faint (resembling jasmine flower smell originating from around ovary) and can only be detected up to $5 \mathrm{~cm}$ away. The nectar was stored on the free calyx and near the base of the petal. The odor persisted for 16-17 hours. The female anthesis started at c. 01:30 am indicated by the glistening and sticky stigma with the petals fully expanded by 02:00 am. The male anthesis began at c. 03:30 am (Day 1). The anthesis only lasted a few hours with the male anthesis ended by 11:00 am (Day 1) and the female anthesis, an hour later. Durio griffithii displayed heterostyly as the pistils were either longer or shorter than stamens (Table 2). All floral organs except the gynoecium abscised by the next morning which indicated successful pollination. The duration to reach fruit maturation was 30 to 40 days. The nectar production began at $01.00 \mathrm{am}$ on the first day of anthesis and ended by $05.00 \mathrm{pm}$ on the same day.

A day before anthesis, c. 10:00 am, the epicalyx of $D$. graveolens began to split to expose the calyx (Figure 8). The calyx began to split at 03:00 am (Day 1) to reveal the petals which extended its length and reflexed by $02: 00 \mathrm{pm}$ (Day 1). The floral odor resembling sugarcane smell was detected up to $5 \mathrm{~m}$ away and persisted for the next 15 to 16 hours. The nectar was stored in the calyx and sometimes near the base of the petal. The female anthesis started in the afternoon, 02:00 pm (Day 1) and followed by the male anthesis, three hours later with the anther slit opened to extrude the powdery pollen. The female and male anthesis ended at the same time, 10:00 am (Day 2). All floral organs except for the gynoecium and stamens abscised by three to four days after anthesis which indicated that the flower was successfully pollinated. The flowers of $D$. graveolens exhibited reverse herkogamy as the stigma was held below the anthers (Table 2). The duration to reach fruit maturation was 70 to 90 days. The nectar production began at 04.00 $\mathrm{pm}$ on the first day of anthesis and ended by $08.00 \mathrm{am}$ on the following day. 


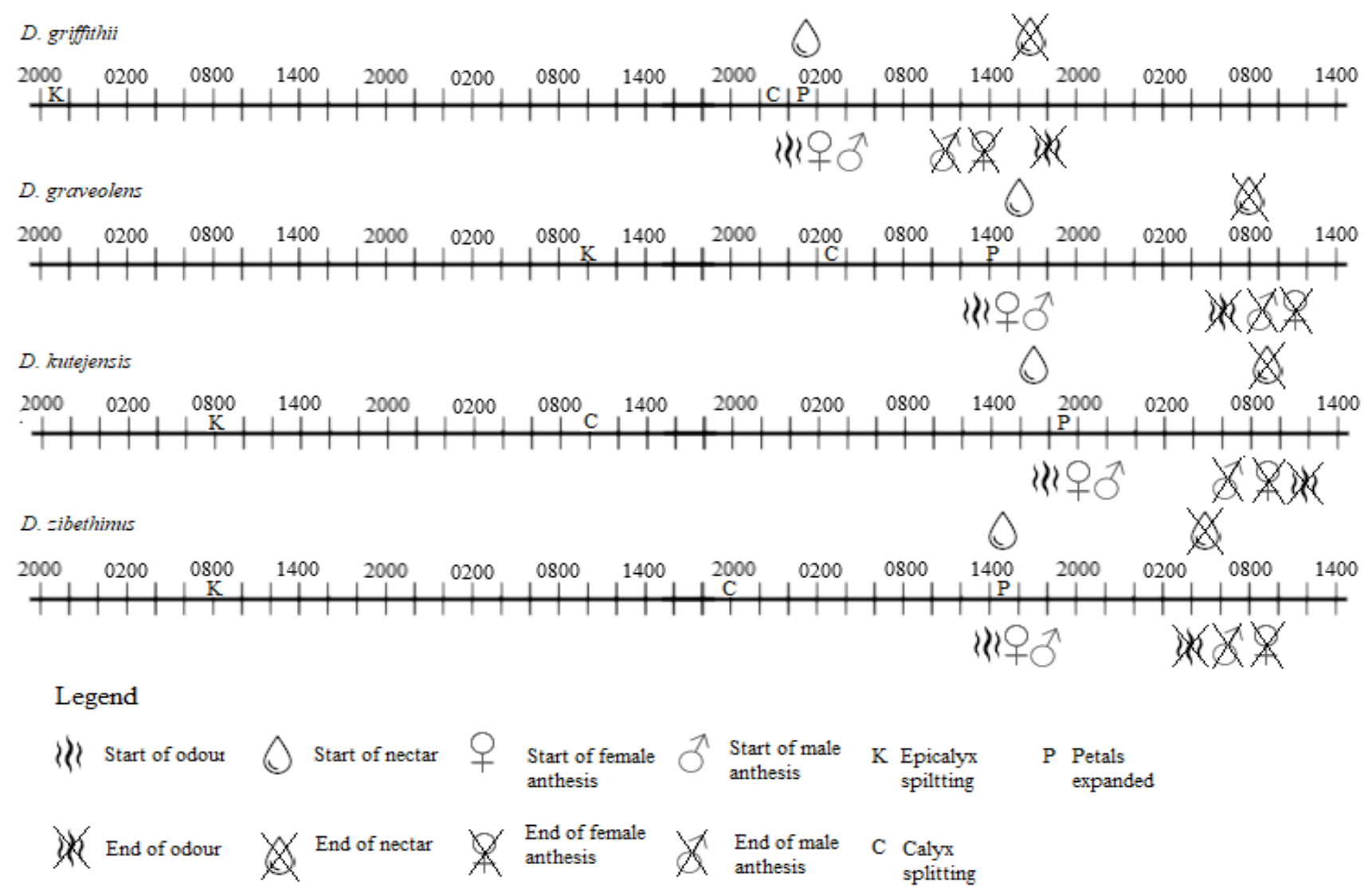

Figure 7. A timeline of the floral events for each species

A day before anthesis, c. 08:00 am the epicalyx of $D$. kutejensis began to split to expose the calyx (Figure 8). The calyx began to split at 10:00 am (a day before anthesis) to reveal the petals which extended its length and reflexed by 07:30 pm (Day 1). The floral odor resembling rotten mango smell was detected up to $20 \mathrm{~m}$ away and persisted for the next 14 to 15 hours. The nectar was stored in the calyx and sometimes near the base of the petal. The female anthesis started at 08:00 pm (Day 1) and followed by the male anthesis, an hour later with the anther slit opened to extrude the powdery pollen. Male anthesis ended at 08:00 am (Day 2) and female anthesis ended an hour later. This species displayed approach herkogamy as the stigma was held above the stamens (Table 2). All floral organs except for the gynoecium and petals abscised by three or four days post-anthesis which indicated that the flower was successfully pollinated. The duration to reach fruit maturation was 80 to 90 days in $D$. kutejensis. The nectar production began at $04.30 \mathrm{pm}$ on the first day of anthesis and ended by $08.30 \mathrm{pm}$ on the next day.

Two days before anthesis, c. 08:00 am the epicalyx of D. zibethinus began to split to expose the calyx (Figure 8). The calyx began to split at 08:00 pm (a day before anthesis) to reveal the petals which extended its length and reflexed by 02:30 pm (Day 1). The floral odor resembling sugarcane smell was detected up to $5 \mathrm{~m}$ away and persisted for the next 14 to 15 hours. The female anthesis started at 02:30 pm (Day 1) and followed by the male anthesis, two hours later with the anther slit opened to extrude the powdery pollen. The male anthesis ended at 04:30 am (Day 2) while the female anthesis ended by 09:00 am (Day 2). This species displayed approach herkogamy as the stigma was held above the stamens (Table 2). All floral organs except for the gynoecium abscised by the next day after anthesis which indicated that the flower was successfully pollinated. The duration to reach fruit maturation was 90 to 100 days. The nectar production began at $02.30 \mathrm{pm}$ on the first day of anthesis and ended by $04.30 \mathrm{pm}$ on the next day.

\section{Floral nectar availability}

Overall, the nectar volume of $D$. griffithii was the lowest compared to the other Durio spp. The nectar volume of $D$. griffithii remained inconsistent and was significantly different $\left(F_{\text {calc. }}, 9.195>F_{\text {crit. }}, 2.27, \alpha<0.05\right)$, ranging from $3.12 \pm 1.57 \mu \mathrm{L}$ to $17.84 \pm 2.32 \mu \mathrm{L}$ throughout the anthetic period with the highest volume recorded at 17.84 $\mu \mathrm{L}, 05: 00$ am, Day 1 . However, the volume was significantly reduced from 11:00 am onwards until the end of anthesis, at 05.00 pm, $3.58 \pm 1.63 \mu \mathrm{L}$. The nectar concentration of $D$. griffithii was similar ( $\mathrm{F}_{\text {calc, }}, 1.922<\mathrm{F}_{\text {crit. }}, 2.27, \alpha>0.05$ ) throughout the anthesis, ranging from $7.56 \pm 0.92 \%$, at $09.00 \mathrm{am}$, Day 1 to $4.92 \pm 0.87 \%$, at $05.00 \mathrm{pm}$, Day 1 .

The nectar volume of $D$. graveolens was recorded at 14 $\pm 4.18 \mu \mathrm{L}$, at the start of production, $04.00 \mathrm{pm}$ (Day 1) and increased to $35 \pm 11.18 \mu \mathrm{L}$, at 12.00 am but decreased to 
$28 \pm 5.70 \mu \mathrm{L}$, at 08.00 am (Day 2) where it ended. The nectar volume was significantly different as the anthesis developed ( $\left.\mathrm{F}_{\text {calc. }}, 3.496>\mathrm{F}_{\text {crit. }}, 2.27, \alpha<0.05\right)$. At the start of anthesis of $D$. graveolens, the nectar concentration was low, $9.40 \pm 0.81 \%$, at $04.00 \mathrm{pm}$, Day 1 and increased to $14.08 \pm 1.40 \%$, at $10.00 \mathrm{pm}$ (Day 1) but decreased until $4.96 \pm 0.62 \%$, at 06.00 am (Day 2) (significantly different, $\mathrm{F}_{\text {calc. }}$ 38.05 $\left.>\mathrm{F}_{\text {crit. }}, 2.27, \alpha<0.05\right)$.

Durio kutejensis produced the highest nectar volume among four species, $4.58 \pm 1.72 \mathrm{~mL}$. The volume increased from $0.87 \pm 0.42 \mathrm{~mL}$, at $04.30 \mathrm{pm}$ (Day 1) to $4.58 \pm 1.72$ $\mathrm{mL}$ at $12.30 \mathrm{am}$ (Day 1). From then onwards, the volume decreased to $3.08 \pm 1.06 \mathrm{~mL}$, at 02.30 am (Day 1), and remained similar until 08.30 am with volume of $2.20 \pm$ $0.91 \mathrm{~mL}$ (Day 2). There was a significant difference in the volume output as the anthesis developed ( $F_{\text {calc. }}, 4.306>$ $\left.F_{\text {crit. }}, 2.15, \alpha<0.05\right)$. The nectar concentration increased from $7.60 \pm 0.58 \%$, at $04.30 \mathrm{pm}$ (Day 1) to $11.33 \pm 1.38 \%$, at $08.30 \mathrm{pm}$ (Day 1) but decreased to $5.63 \pm 0.74 \%$, at 08.30 am (Day 2) ( $\left.F_{\text {calc. }}, 37.80>F_{\text {crit. }}, 2.15, \alpha<0.05\right)$.

The nectar volume of $D$. zibethinus increased from 0.27 $\pm 0.08 \mathrm{~mL}$ at $02.30 \mathrm{pm}$ (Day 1 ) to $0.77 \pm 0.11 \mathrm{~mL}$, at 08.30 pm (Day 1). Since then, the volume remained similar to $0.73 \pm 0.11 \mathrm{~mL}, 02.30$ am (Day 2) but decreased to $0.43 \pm$ $0.10 \mathrm{~mL}$, at 04.30 am (Day 2). The volume was significantly different as the anthesis developed $\left(\mathrm{F}_{\text {calc. }}\right.$,
$\left.18.93>\mathrm{F}_{\text {crit }} 2.25, \alpha<0.05\right)$. The nectar concentration also followed a similar trend for $D$. zibethinus with an increment from $02.30 \mathrm{pm}$ at $13.00 \pm 1.47 \%$ on Day 1 to around $10.30 \mathrm{pm}$ at $15.80 \pm 0.62 \%$ and finally decreased at $04.30 \mathrm{am}, 13.80 \pm 0.94 \%$ the next day (Day 2$)\left(\mathrm{F}_{\text {calc. }}, 6.682\right.$ $\left.>\mathrm{F}_{\text {crit. }}, 2.25, \alpha<0.05\right)$

\section{Breeding mechanism}

The fruit set of the bagged flowers of (T1), manual cross-pollination (T2), open pollination (T3), and selfing (T3) for D. griffithii were $58.54 \%, 83.33 \%, 78.05 \%$, and $65.12 \%$ respectively (Table 3 ). On Day 10 , only 3 out of $41(7.32 \%)$ fruit development remained for $\mathrm{T} 1$ with the fruit sets of the other treatments were reduced to $28.57 \%$ (T2), $34.15 \%$ (T3), and $25.58 \%$ (T4) respectively. For $D$. graveolens, fruit sets of T1, T2, T3, and T4 were: $54.29 \%$, $41.94 \%, 39.39 \%$, and $38.24 \%$ on Day 3. Fruit set was further reduced by Day 10: 14.29\% (T1), $19.35 \%$ (T2), $18.75 \%$ (T3), and $14.71 \%$ (T4) respectively. As for $D$. zibethinus, the fruit sets were: $39.39 \%$ (T1), 59.94\% (T2), $58.82 \%$ (T3), and $46.67 \%$ (T4) respectively. At Day 10, fruit sets were further reduced: $6.06 \%$ (T1), $16.13 \%$ (T2), $14.71 \%$ (T3), and $19.36 \%$ (T4) respectively. Although heterostyly exists within $D$. griffithii, fruit set still occurs within and between the two morphs.

Table 2. Length of pistil and stamen one hour before and during anthesis in millimeter, $\mathrm{mm}(\mathrm{N}=20)$

\begin{tabular}{llccccc}
\hline & & \multicolumn{2}{c}{ Durio griffithii } & \multirow{2}{*}{ Durio graveolens } & Durio kutejensis & Durio zibethinus \\
\cline { 2 - 6 } & & Long pistil & Short pistil & & \\
\hline Pistil length & One hour before anthesis & $8.84 \pm 0.14$ & $5.54 \pm 0.03$ & $28.52 \pm 0.23$ & $78.12 \pm 0.67$ & $26.81 \pm 0.43$ \\
& During anthesis & $11.99 \pm 0.10$ & $8.03 \pm 0.04$ & $39.71 \pm 0.13$ & $90.08 \pm 1.21$ & $56.31 \pm 0.14$ \\
Stamen length & One hour before anthesis & $7.45 \pm 0.09$ & $7.35 \pm 0.12$ & $30.67 \pm 1.12$ & $62.78 \pm 0.42$ & $31.21 \pm 0.39$ \\
& During anthesis & $10.89 \pm 0.08$ & $10.79 \pm 0.09$ & $50.61 \pm 0.91$ & $83.98 \pm 0.88$ & $52.67 \pm 0.21$ \\
\hline
\end{tabular}

Table 3. Fruit set for pollination treatments of Durio griffithii, D. graveolens, and D. zibethinus. Numbers in parenthesis represent the number of fruits/ number of flowers.

\begin{tabular}{|c|c|c|c|c|c|c|c|c|}
\hline \multicolumn{9}{|c|}{ Fruit set (\%) } \\
\hline & \multicolumn{2}{|c|}{ Bagged } & \multicolumn{2}{|c|}{ Cross } & \multicolumn{2}{|c|}{ Open } & \multicolumn{2}{|c|}{ Self-pollinated } \\
\hline & Day 3 & Day 10 & Day 3 & Day 10 & Day 3 & Day 10 & Day 3 & Day 10 \\
\hline D. griffithii & $\begin{array}{c}58.54 \pm 0.50 \\
(24 / 41)\end{array}$ & $\begin{array}{c}7.32 \pm 0.26 \\
(3 / 41)\end{array}$ & $\begin{array}{c}83.33 \pm 0.38 \\
(35 / 42)\end{array}$ & $\begin{array}{c}28.57 \pm 0.48 \\
(12 / 42)\end{array}$ & $\begin{array}{c}78.05 \pm 0.42 \\
(32 / 41)\end{array}$ & $\begin{array}{c}34.15 \pm 0.48 \\
(14 / 41)\end{array}$ & $\begin{array}{c}65.12 \pm 0.48 \\
(28 / 43)\end{array}$ & $\begin{array}{c}25.58 \pm 0.44 \\
(11 / 43)\end{array}$ \\
\hline D. graveolens & $\begin{array}{c}54.29 \pm 0.51 \\
(19 / 35)\end{array}$ & $\begin{array}{c}14.29 \pm 0.36 \\
(5 / 35)\end{array}$ & $\begin{array}{c}41.94 \pm 0.50 \\
(21 / 3)\end{array}$ & $\begin{array}{c}19.35 \pm 0.40 \\
(6 / 31)\end{array}$ & $\begin{array}{c}39.39 \pm 0.50 \\
(13 / 3)\end{array}$ & $\begin{array}{c}18.18 \pm 0.39 \\
(6 / 33)\end{array}$ & $\begin{array}{c}38.24 \pm 0.49 \\
(13 / 33)\end{array}$ & $\begin{array}{c}14.71 \pm 0.36 \\
(5 / 34)\end{array}$ \\
\hline D. zibethinus & $\begin{array}{c}39.39 \pm 0.49 \\
(13 / 33)\end{array}$ & $\begin{array}{c}6.06 \pm 0.24 \\
(2 / 33)\end{array}$ & $\begin{array}{c}59.38 \pm 0.50 \\
(19 / 3)\end{array}$ & $\begin{array}{c}15.63 \pm 0.37 \\
(5 / 32)\end{array}$ & $\begin{array}{c}58.82 \pm 0.50 \\
(20 / 3)\end{array}$ & $\begin{array}{c}14.71 \pm 0.36 \\
(5 / 34)\end{array}$ & $\begin{array}{c}45.16 \pm 0.50 \\
(14 / 33)\end{array}$ & $\begin{array}{c}19.35 \pm 0.40 \\
(6 / 30)\end{array}$ \\
\hline
\end{tabular}

Table 4. Self-Incompatibility Index (ISI) and self-incompatibility based on fruit set

\begin{tabular}{llll}
\hline & ISI & Self-compatibility based on ISI & Self-compatibility based on fruit set \\
\hline D. griffithii & 0.90 & Partially self-incompatible & Class 1, slightly self-incompatible \\
D. graveolens & 0.74 & Partially self-incompatible & Class 1, slightly self-incompatible \\
D. zibethinus & 1.20 & Self-incompatible & Class 1, slightly self-incompatible \\
\hline
\end{tabular}


Based on the ISI score, D. griffithii and D. graveolens were partially self-incompatible $(0.74$ and 0.90 , respectively; Table 4). The self-incompatibility rate was also supported based on the fruit set of both species. Both species were classified as Class 1 (slightly selfincompatible) with fruit set from artificial self-pollination at $25.58 \%$ and $14.71 \%$ respectively (Table 3 ). Durio zibethinus was a self-incompatible species based on the ISI score, 1.20. However, D. zibethinus was placed as Class 1 (slightly self-incompatible) based on the fruit set, $19.35 \%$.

\section{Floral visitors}

Flowers of $D$. griffithii were visited by honey bees (Apis dorsata, Apidae), between 06:00 am to 11:00 am (Day 1), stingless bees (Trigona spp., Apidae), between 06:00 am to 05:00 pm (Day 1), thrips, between 07:00 am to 12:00 pm (Day 1), and pollen beetles, between 06:00 am to 05:00 pm (Day 1) (Figures 9 and 10). The average number of visits per hour and duration of visits were: 2 and $14 \mathrm{sec}$ (honey bees), 4 and $72 \mathrm{sec}$ (stingless bees), 6 and $28.4 \mathrm{~min}$ (thrips), and 3 and $15.2 \mathrm{~min}$ (pollen beetles). Honey bees foraged on the flowers near the anthers and collected pollen. Stingless bees, thrips, and pollen beetles mainly fed on the nectar. Pollen beetles were also observed to feed on the pollen and the staminodes. All aforementioned floral visitors touched the stigma and stamens and their visits coincided with the anthetic period; thus, all these visitors are suggested to be possible pollinators of $D$. griffithii. The visiting period of each visitor and the number of insect individuals recorded during visit are presented in Figure 9.

Flowers of $D$. graveolens were visited by honey bees, between 06:00 am to 10:00 am (Day 2), stingless bees, between $02.00 \mathrm{pm}$ to $06.00 \mathrm{pm}$ (Day 1) and 06:00 am to 10:00 am (Day 2), bats, between 09:30 pm (Day 1) to 12:30 am (Day 2), and pollen beetles, between 02:00 pm to 07:00 pm (Day 1) and 06.00 am to 10.00 am (Day 2) (Figures 9 and 10). The average number of visits per hour and duration of visits were: 2 and $25 \mathrm{sec}$ (honey bees), 3 and $15 \mathrm{sec}$ (stingless bees), 9 and $1 \mathrm{sec}$ (bats), and 3 and $19.4 \mathrm{~min}$ (pollen beetles). The visiting time of visitors coincided with the anthetic period and thus all visitors are suggested to be possible pollinators of $D$. graveolens. Behavioral patterns of honey bees, stingless bees, and pollen beetles were similar to those in $D$. griffithii. Fruit bats [most probably dawn bat, Eonycteris spelaea (Pteropodidae)] were observed to hover above the flowers directly and insert its head into the flowers to feed on the nectar. Other secondary visitors that were occasionally observed but did not come into contact with both stigma and stamens include carpenter bees (Xycolopa latipes, Hymenoptera) and cockroaches (Blattodea). The carpenter bees were observed to visit $D$. graveolens around $02: 00 \mathrm{pm}$ to $07.00 \mathrm{pm}$ (Day 1) and 06.00 am to 10:00 am (Day 2) with an average of two individuals per hour and visiting time, was 8 sec. Cockroaches were found on $D$. graveolens around $06.30 \mathrm{pm}$ (Day 1) to 06.30 am (Day 2) ) with an average of two individuals per hour and visiting time, was $21.3 \mathrm{~min}$ and was observed to consume pollen.

Flowers of D. kutejensis were visited by honey bees, between 05.45am to 06.30 am (Day 2), stingless bees, between 06.00 am to 08.00 am (Day 2), nocturnal wasps (Provespa sp.), between $06.30 \mathrm{pm}$ (Day 1) to $04.30 \mathrm{am}$ (Day 2), bats, between 09:30 pm (Day 1) to 12:30 am (Day 2), and birds, between 06:00 am to 09:00 am (Day 2) (Figures 9 and 10). The average number of visits per hour and duration of visits were: 62 and $6 \mathrm{sec}$ (honey bees), 26 and $21 \mathrm{sec}$ (stingless bees), 6 and $7 \mathrm{sec}$ (nocturnal wasps), 3 and $1 \mathrm{sec}$ (bats), and 3 and $4 \mathrm{sec}$ (birds). The visiting time of visitors coincided with the anthetic period and thus all visitors are suggested to be possible pollinators of $D$. kutejensis. Spiderhunters (Arachnothera sp.) were observed to touch the stigma and anthers when they sucked nectar from flowers. Behavioral patterns among the honey bees, stingless bees, bats, and pollen beetles were similar to other Durio species. However, honey bees were observed to be extensively covered with pollen. Nocturnal wasps were only observed in this species and have similar foraging habits as honey bees or stingless bees. The wasps visited in large swarms. Other secondary visitors that were occasionally observed but did not come into contact with both stigma and stamens include carpenter bees (Xycolopa latipes, Hymenoptera) and cockroaches (Blattodea). The carpenter bees were observed to visit $D$. kutejensis around $07.00 \mathrm{am}$ to $09.00 \mathrm{am}$ (Day 2) with an average of three individuals per hour and visiting time, was $9 \mathrm{sec}$. Cockroaches were found on D. kutejensis around $08.30 \mathrm{pm}$ (Day 1) to 05.30 am (Day 2) with an average of two individuals per hour and visiting time, was $28.3 \mathrm{~min}$ and was observed to consume pollen.

Flowers of $D$. zibethinus were visited by stingless bees, between $02.30 \mathrm{pm}$ to $07.00 \mathrm{pm}$ (Day 1), bats, between 09:30 pm (Day 1) to 12:30 am (Day 2), and pollen beetles, 06:30 pm (Day 1) to 03:30 am (Day 2). The average number of visits per hour and duration of visits were: 3 and $13 \mathrm{sec}$ (stingless bees), 7 and $1 \mathrm{sec}$ (bats), and 3 and 24.2 min (pollen beetles). The visiting time of visitors coincided with the anthetic period and thus all visitors are suggested to be possible pollinators of $D$. zibethinus. Behavioral patterns among the stingless bees, bats, and pollen beetles were similar as in other species. Other secondary visitors that were occasionally observed but did not come into contact with both stigma and stamens include carpenter bees (Xycolopa latipes, Hymenoptera) and cockroaches (Blattodea) (Figure 11). The carpenter bees were observed to visit $D$. zibethinus around $02.30 \mathrm{pm}$ until $07.00 \mathrm{pm}$ (Day 1) with an average of two individuals per hour and visiting time, was $9 \mathrm{sec}$. Cockroaches were found on D. kutejensis around $08.30 \mathrm{pm}$ (Day 1) to 04.30 am (Day 2) with an average of two individuals per hour and visiting time, was $20.3 \mathrm{~min}$ and was observed to consume pollen. 


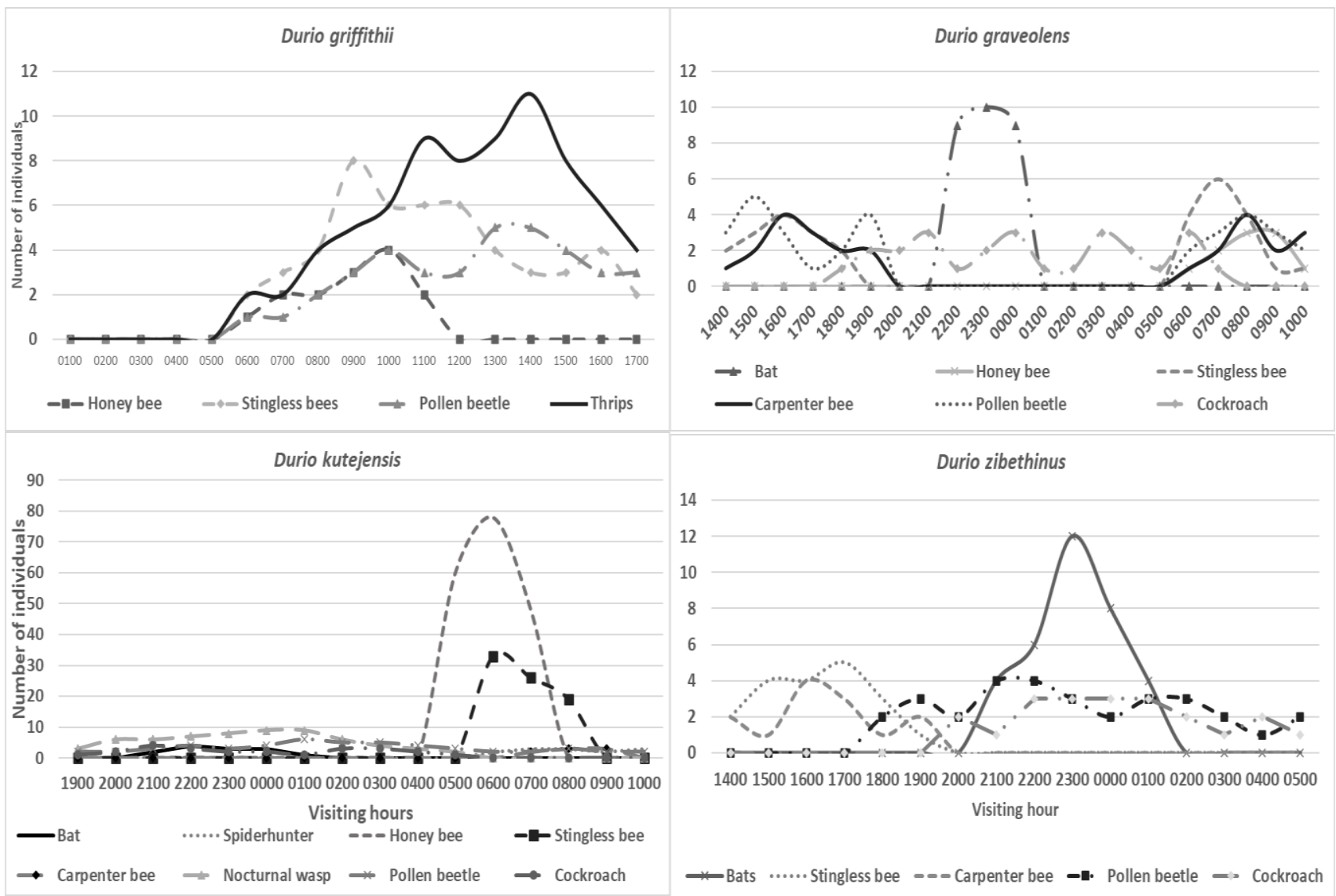

Figure 8. Visiting period of each visitor and number of individuals recorded
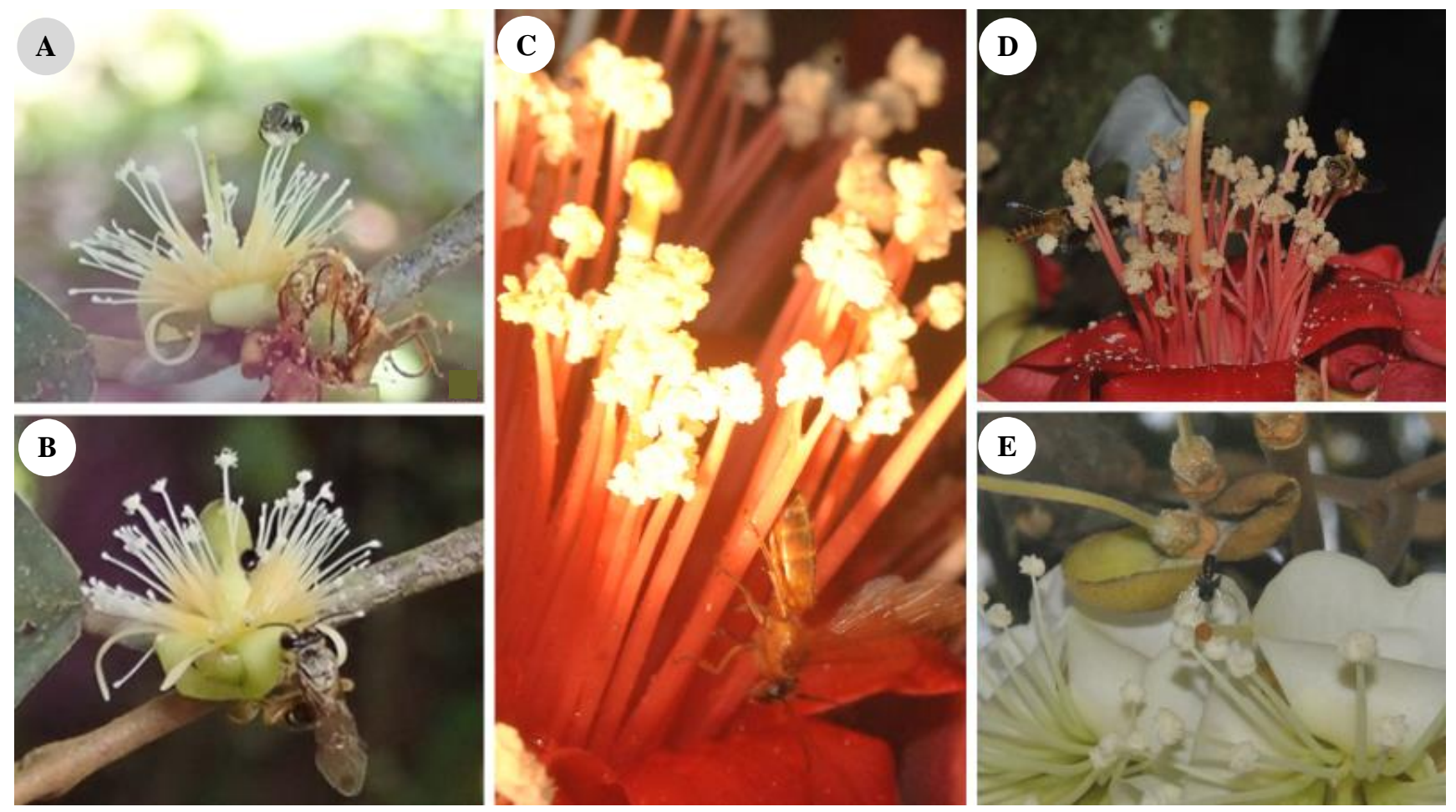

Figure 10. Floral visitors recorded: A. Stingless bee visiting Durio griffithii, B. Pollen beetle and honey bee visiting D. griffithii, C. Nocturnal wasp visiting $D$. kutejensis, D. Honey bees visiting $D$. kutejensis, E. Stingless bee visiting D. graveolens 

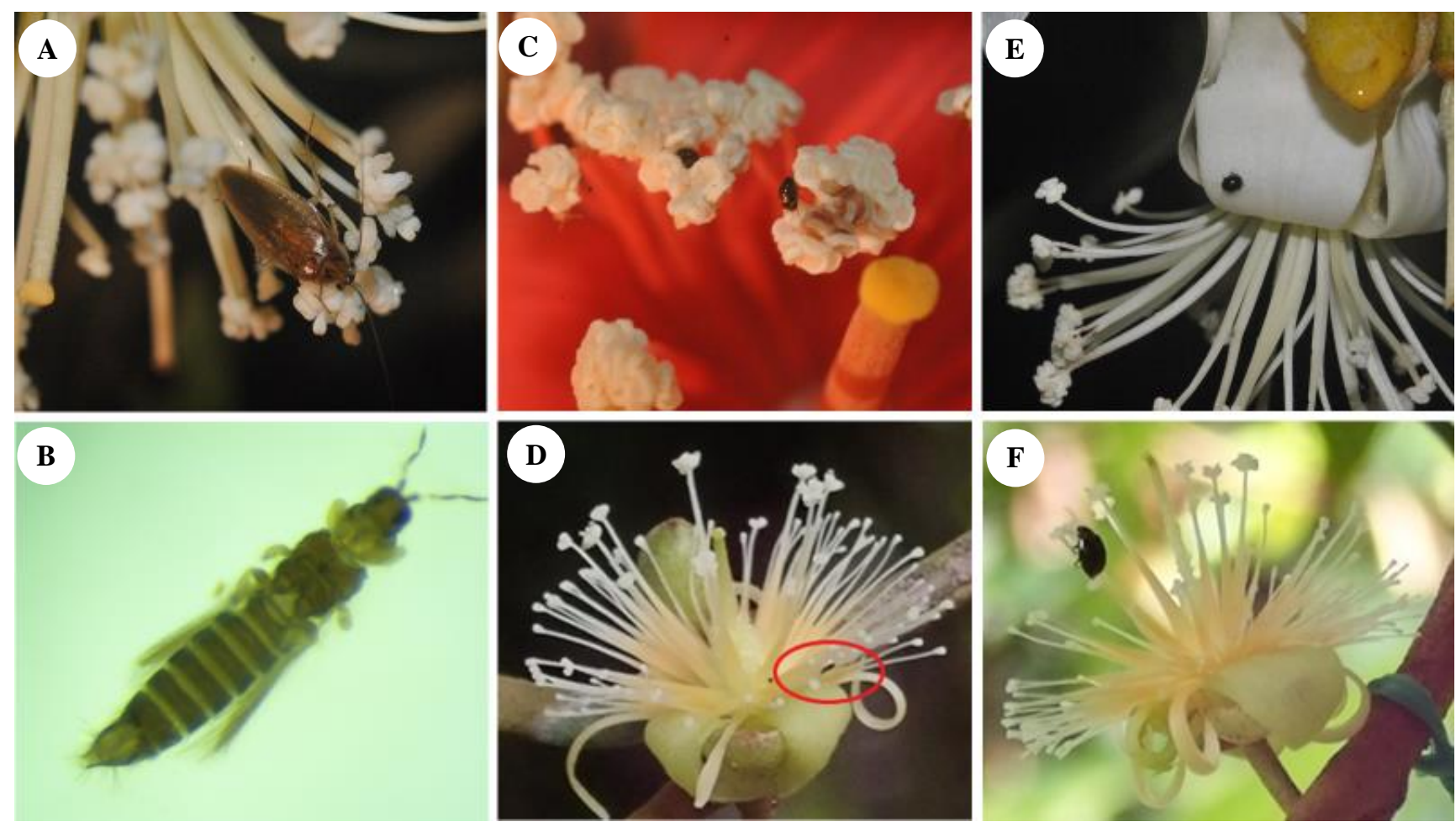

Figure 11. Floral visitors recorded: A. Cockroach visiting Durio zibethinus, B. Thrip viewed under dissecting microscope. C. Pollen beetles visiting $D$. kutejensis, D. Pollen beetle visiting D. griffithii, E. Pollen beetle visiting D. zibethinus, F. Pollen beetle visiting $D$. griffithii

\section{Discussion}

\section{Floral biology}

The flowering period of $D$. zibethinus and $D$ graveolens was observed to occur from July to October, although flowering of these Durios are most likely to be influenced by a period of water stress (Suwanseree and Yapwattanaphun 2017). Although raining occurs yearround in Malaysia, these region experiences periods of Monsoon season characterized by periods of heavy rain-fall which is shifting due to climate change (Tang 2019) and will likely have adverse effects on the flowering periods of these Durios. The time-course of flower opening shows that the anthesis started in the afternoon for D. graveolens and $D$. zibethinus, evening for $D$. kutejensis but midnight for $D$. griffithii. The anthesis lasted for 11.5 hours $(D$. griffithii), 20 hours (D. graveolens), 13 hours (D. kutejensis), and 17.5 hours (D. zibethinus). However, Yumoto's (2000) observation showed that D. kutejensis opened at c. $04.30 \mathrm{pm}$ which is much earlier compared to the results of this paper (c. $08.00 \mathrm{pm}$ ) although both can be considered as nocturnal anthesis. Nevertheless, Yumoto (2000) did not specify the exact time of female and male anthesis but only the blooming time. Yumoto (2000) also confirmed that the blooming time of $D$. oblongus, a close ally of $D$. griffithii is $02.00 \mathrm{pm}$ while based on our observations, D. griffithii bloomed around $01.00 \mathrm{am}$. This difference is to be expected as the floral characters of $D$. oblongus were typical of ornithophily and chiropterophily and were mainly pollinated by diurnal spiderhunters (Nectariniidae) (Yumoto 2000). The floral characters of $D$. graveolens and $D$. zibethinus were both very similar (petal color, floral shape, scent, and nectar production) and thus attracted similar floral visitors.

In this present study, stigma of $D$. zibethinus became receptive around $04.30 \mathrm{pm}$ while anther dehiscence occurred around two to three hours later around $06.30 \mathrm{pm}$. This result conforms with previous studies albeit with differences of one to two hours, most likely owing to different localities (Lim and Luders 1998; Bumrungsri et al. 2009).

\section{Dichogamy, herkogamy, reverse herkogamy and distyly}

Dichogamy which serves as a temporal separation of pollen reception and deposition has been previously observed in D. zibethinus ( $\operatorname{Lim}$ and Luders 1998; Bumrungsri et al. 2009; Wayo et al. 2018). All Durio species observed in this study display protogyny. The stigma receptivity occurs before anther dehiscence with a delay time of three hours in $D$. graveolens, two hours in $D$. griffithii, one to two hours in D. kutejensis and two to three hours in D. kutejensis

Different forms of herkogamy were observed in all the Durio spp. studied; distylous heterostyly in D. griffithii, reverse herkogamy in D. graveolens, approach herkogamy in D. kutejensis, and D. zibethinus. Fruit set occurred between both morphs of D. griffithii in selfing and crosspollination experiments. However, intra-flower selfing is largely prevented by the relative position of the stigmas and anthers. Plant that exhibits heterostyly typically has a heteromorphic incompatibility system that prevents 
intramorph mating, however, exceptions have been observed (Zapata and Arroyo 1978). Heterostyly has also been confirmed in $D$. zibethinus, however, not all varieties/clones exhibit heterostyly. Lim and Luders (1998) on the other hand, concluded that several cultivars of $D$. zibethinus do not exhibit heterostyly but instead exhibit reverse herkogamy. Within Malvaceae, two other genera, Waltheria L. and Melochia L. are confirmed to display heterostyly in several species (Faife-Cabrera et al. 2014). Heterostyly functions to increase efficiency of crosspollination and at the same time avoiding self-interference between male and female sexual organs which is achieved through a spatial gap between the anther and stigma that is enough to reduce the odds of self-pollination. The spatial gap influences pollen dispersal and male reproductive success through plant-pollinator interactions.

\section{Self-incompatibility in Durio}

Durio griffithii, D. graveolens, and D. zibethinus are shown to be partial to self-incompatible based on ISI and fruit set values. The results of this study are congruent with a study by Bumrungsri and colleagues (2009) on semi-wild D. zibethinus in southern Thailand. Plant species that generally prefers outcrossing as oppose to selfers by a series of traits such as more and larger flowers, higher nectar production, stronger floral scents, more pollen grains, more significant proximity between anther and stigma, more ovules but lower relative seed production (Dafni 1992). Yumoto (2000) suggested that D. grandiflorus, D. oblongus and D. kutejensis are selfincompatible. There are at least six Durio species that are self-incompatible representing all three major clades proposed by Nyffeler and Baum (2001) which allows a reasonable assumption that majority of Durio is primarily self-incompatible. Although the observed Durio spp. were characterized as self-incompatible based on our pollination systems, selfing still occurs in three species. Selfincompatibility is a plastic trait where its strength can be influenced by environmental conditions (e.g. temperature), internal stylar conditions such as the age of the flowers, mutations affecting S-alleles strength by mutations causing S-allele to lose its function, and unlinked genetic modifiers affecting S-alleles strength within the population. Compromised self-incompatibility systems cause pseudoself-compatibility to occur allowing seed set to occur in primarily self-incompatible populations that have been previously reported in many families (Baldwin and Schoen 2017; Harkness 2017; Balogh and Barrett 2018).

Late-acting self-incompatibility was observed in $D$. griffithii, D. graveolens, and D. zibethinus. This selfincompatibility mechanism where there is a significant drop in fruit set was also previously observed on $D$. zibethinus (Bumrungsri et al. 2009; Wayo et al. 2018). Lim and Luders (1998) suggest that this late-acting selfincompatibility mechanism is gametophytically controlled based on their observations; aborted growth in pollen tubes in the stylar tissues, moist and sticky stigma during anthesis, binucleate pollen grains which germinated readily, and viable pollen in long term storage.

\section{Floral nectar}

The calyx of D. graveolens, D. kutejensis, and D. zibethinus is campanulate to almost cupulate in $D$. zibethinus which allowed nectar storage. The calyx also allows the nectar not to be spilled over quickly even in strong winds. Owing to the large surface area within the calyx, the nectar could adhere to the calyx wall through surface tension. In $D$. griffithii, the much smaller flowers have free calyx lobes and thus store lower volume of nectar. The volume also fluctuates with no discernible patterns as compared to the other three Durio species. This might be owing to the inability of the calyx of $D$. griffithii to store the nectar. In D. graveolens, D. kutejensis, and D. zibethinus where nectar production is the highest at night, from $10.00 \mathrm{pm}$ to $02.00 \mathrm{am}$, coincided with the timing of bat visitations. Pollen beetles were observed to consume the pollen of all species but also fed on the staminodes of D. griffithii. Nitidulidae is known for feeding on sterile floral structures in other plant families (Hoe et al. 2018; Low et al. 2018).

Our results on D. kutejensis is similar to Yumoto (2000) as the nectar peaked towards midnight. However, the nectar production in Yumoto's observation remained more or less the same towards the end of production, our results showed a decline in production towards the end. Nectar production can be energy costly, therefore it is unsurprising for plants to adjust for production rate based on intensity of consumption and reabsorb unconsumed nectar (Heil 2011). The change in nectar volume and concentration also changes with air temperature and humidity and thus should be considered to fully understand the nectar production. For D. zibethinus, Bumrungsri and colleagues (2009) reported nectar output was maximum during early evening and reduced as the evening progressed.

\section{Pollinators}

One species of fruit bats, E. spelaea was observed to visit D. graveolens, D. kutejensis, and D. zibethinus while spiderhunter, Arachnotera sp. was found to visit $D$. kutejensis only. Bat pollination in Durio has been long known (Soepadmo and Eow 1977; Bumrungsri et al. 2009; Maas et al. 2016; Sritongchuay and Bumrungsri 2016; Sritongchuay et al. 2016; Stewart and Dudash 2016; Sheema et al. 2017; Thavry et al. 2017; Chaiyarat et al. 2019; Sritongchuay et al. 2019; Tsang and Wiantoro 2019; Sheherazade et al. 2020). Several features of the flower (e.g., whitish or creamy petal color, large flowers, large anthers, cauliflory) are amenable to bat pollination. Yumoto (2000) found that D. grandiflorus, D. oblongus, and $D$. kutejensis were pollinated by spiderhunters but $D$. kutejensis was also pollinated by bats and bees. Vertebrate pollination has been confirmed in /Cullenia clade, /Boschia (D. grandiflorus), /Palatadurio clade (Durio zibethinus, D. graveolens, D. kutejensis), and /Tubulidurio clade (D. oblongus) making this particular pollination system as plesiomorphic for Durio s. lat. + Cullenia alliance (Nyffeler and Baum 2001).

Seven invertebrate taxa were observed as the main floral visitors of Durio spp., studied: honeybee, Apis sp. (Apidae), carpenter bee, Xycolopa latipes (Apidae), 
stingless bee, Tetrigona sp. (Apidae), nocturnal wasp, Provespa sp. (Vespidae), pollen beetle (Nitidulidae), cockroach (Blattodea), and thrip (Thysanoptera). Yumoto (2000) had also previously observed and deduced that $D$. kutejensis are pollinated by honeybees (Apis dorsata) as well. Durio griffithii was reported to be pollinated by bees (Momose et al. 1998). However, Apis sp. observed to visit D. griffithii in this study had a different visiting period as compared to D. kutejensis. In D. kutejensis, the honeybees visited in a large number for a short duration, from 05.45am to 06.30 am whereas in D. griffithii and $D$. graveolens, the honeybees visit for a longer period in much smaller number from 06.00 am to 11.00 am. Yumoto (2000) did not consider Tetrigona sp. as a potential pollinator of $D$. kutejensis as the stingless bees did not come in contact with the flowers. This contradicts the observations in this study where the stingless bees collected pollen and fed on the nectar which is similar to the visiting habit of Apis sp.; thus Tetrigona sp. can also be considered as a potential pollinator for all four observed species. Apis cerana was reported to pollinate $D$. zibethinus in West Sumatra (Jasmi 2017). Thrips were also listed as pollinators for D. griffithii (Lee et al. 2002). Thrips are important pollinators in other tropical plant families (Heckenhauer et al. 2018; Chai and Wong 2019).

The nocturnal wasps, Provespa were observed to visit only D. kutejensis despite there are two other Durio species in the same vicinity. It is highly likely that the nocturnal wasps visited $D$. kutejensis for opportunistic reasons as members of this group are known to swarm when initiating a new nest and the flowers of $D$. kutejensis provided the most nectar. This is the first record of members of Provespa visiting Durio. The pollen beetles (Nitidulidae) probably belong to two different groups from two localities (D. graveolens, D. kutejensis, and D. zibethinus vs. D. griffithii) as the elytra looked slightly different although the color was similar.

All observed Durio spp. in this study are visited by variety of vertebrate and invertebrate; thus, it can be said that Durio acts as a generalist species. Although bat pollination has been confirmed by many authors, observations of insect pollination have also been reported albeit with mixed results. While Bumrungsri and colleagues (2009) reported that there is no strong evidence of successful insect pollination in D. zibethinus despite high number of visitors, Wayo and colleagues (2018) reported bees as supplementary pollinators with strong evidence. Sheema and colleagues (2017) also reported high insect interaction but was unable to confirm effective pollination. Perhaps with the high visitation rates, pollination may occur. A shifting trend from primarily chiropterophilous pollination towards entomophilous pollination was suggested by Yumoto (2000) and Nyffeler and Baum (2001). The flowers of D. griffithii are white in color, produce a sweet scent, nectar and easy access to these rewards are largely cantharophilous (beetle pollinated) but are also capable of attracting bees (Apidae). Even though $D$. griffithii had nocturnal anthesis that continued into the daytime, the main animal visitor activities occurred after sunrise. Momose et al. (1998) reported D. griffithii is mainly pollinated by sweat bees (Nomia sp.).

In conclusion, Durio species are one day-duration, nocturnal (at least towards) flowering plants with three pollination guilds: chiropterophily, ornithophily, and entomophily. Self-incompatibility is highly likely but selfing is shown to be possible in all the species investigated. Floral rewards are nectar, pollen, and sterile structures (only in D. griffithii). The production of floral nectar coincides with the peak visitations of bats (except $D$. griffithii).

\section{ACKNOWLEDGEMENTS}

We would like to thank Chiong Heng Hock and his family for allowing us to conduct our research at their farm in Limbang and the staff members at Borsamulu Park for their help during data collection at Mulu National Park. The fieldwork was conducted under Research Permit No. (67) JHS/NCCD/600-7/2/107/Jld.2 and Park Permit No. WL33/2019 from Sarawak Forestry Department. We are grateful to Universiti Malaysia Sarawak (UNIMAS) for facilitating this research. Funding by Ministry of Higher Education Malaysia through Fundamental Research Grant Scheme No. FRGS/1/2020/WAB11/UNIMAS/02/3 is acknowledged.

\section{REFERENCES}

Amid BT, Mirhosseini H. 2012. Optimisation of aqueous extraction of gum durian (Durio zibethinus) seed: A potential, low-cost source of hydrocolloid. Food Chem 132: 1258-1268.

Apuy M, Lahjie AM, Simarangkir BDAS, Ruslim Y, Kristiningrum R. 2017. Traditional plants in forest gardens of West Kutai, Indonesia: Production and financial sustainability. Biodiversitas 18: 1207-1217.

Baldwin SJ, Schoen DJ. 2017. Genetic variation for pseudo-selfcompatibility in self-incompatible populations of Leavenworthia alabamica (Brassicaceae). New Phytol 213: 430-439.

Balogh CM, Barrett SCH. 2018. Genetic and environmental influences on partial self-incompatibility in Lythrum salicaria (Lythraceae). Int J Plant Sci 179: 423-435.

Bumrungsri S, Sripaoraya E, Chongsiri T, Sridith K, Racey PA. 2009. The pollination ecology of durian (Durio zibethinus, Bombacaceae) in southern Thailand. J Trop Ecol 25: 85-92.

Chai SK, Wong SY. 2019. Five pollination guilds of aroids (Araceae) at Mulu National Park (Sarawak, Malaysian Borneo). Webbia 74: 353 371.

Chaiyarat R, Boonma W, Koedrith P. 2019. The role of pteropodid bats in pollination of durian (Durio zibethinus) in managed orchards in suburban habitat of Thailand. Urban Ecosyst 23: 97-106.

Cornelia M, Siratantri T, Prawita R. 2015. The utilization of extract Durian (Durio zibethinus L.) seed gum as an emulsifier in vegan mayonnaise. Procedia Food Sci 3: 1-18.

Dafni A. 1992. Pollination ecology: A Practical Approach. IRL Press, New York.

Faife-Cabrera, M, Ferrero V, Navarro L. 2014. Unravelling the stylar polymorphism in Melochia (Malvaceae): reciprocity and ancillary characters. Bot J Linn Soc 176: 147-158.

Google Earth. 2020. Google Map of Limbang to Mulu. Retrieved 23 August 2019, from https://earth.google.com/web/@4.31159641,111. 54094239,5222.06076926a,1757731.3197577d,35y,0h,0t,0r

Hammer Ø. 2020. PAST: Paleontological Statistics Software Package for Education and Data Analysis. - https://past.en.lo4d.com/windows.

Handayani F. 2016. Genetic diversity of Lai (Durio kutejensis (Hassk.) Becc.) based on morphological and inter-simple sequence repeat 
markers. [Thesis]. Universitas Gadjah Mada, Yogyakarta [Indonesian]

Handayani F, Rahayu SP. 2017. Assessment of genetic diversity in Lai (Durio kutejensis) local cultivars of Batuah (Indonesia) using ISSR marker. Biodiversitas 18: 525-529.

Hariyati T, Kusnadi J, Arumingtyas EL. 2013. Genetic diversity of hybrid durian resulted from crossbreeding between Durio kutejensis and Durio zibethinus based on RAPDs. Am J Mol Biol 3: 153-157.

Harkness A. 2017. Digest: Prudent self denial: The advantage of incompatibility in Leavenworthia alabamica. Evolution 71: 884-897.

Heckenhauer J, Samuel RS, Ashton PS, Abu Salim K, Paun O. 2018 Phylogenomics resolves evolutionary relationships and provides insights into floral evolution in the tribe Shoreeae (Dipterocarpaceae). Mol Phyl Evol 127: 1-13

Heil M. 2011. Nectar: generation, regulation, and ecological functions. Trends Plant Sci 16: 191-200.

Hoe YC, Gibernau M, Wong SY. 2018. Diversity of pollination ecology in the Schismatoglottis Calyptrata Complex Clade (Araceae). Plant Biol 20: 563-78.

Indriyani NLP, Hadiati S, Nasution F, Sudjijo E, Irawati Y. 2012 Maternal and paternal effect on the characters of Durian (Durio zibethinus Murr.) fruit from cross-pollination. J Fruit Ornam Pl R 20: 23-33.

Jasmi. 2017. Diversity and blooming season of food sources plant of Apis cerana (Hymenoptera: Apidae) in polyculture plantation in West Sumatra, Indonesia. Biodiversitas. 18: 34-40.

Jutamanee K, Sirisuntornlak N. 2017. Pollination and fruit set in durian 'Monthong' at various times and with various methods of pollination. Acta Hortic 1186: 121-126.

Kostermans AJGH. 1958. The genus Durio Adans. (Bombacaceae). Reinwardtia 4: 357-460.

Kurniadinata OF, Song W, Rusdiansyah. 2020. Morphological characteristics of batuah red-fleshed durian (Durio graveolens), an endemic exotic plant from East Kalimantan, Indonesia. J Trop Agric 3: $12-18$.

Lee SS, Norsham SY, Boon KS, Chua LSL. 2002. The role of selected animals in pollination and dispersal of trees in the forest: implications for conservation and management. J Trop For Sci 14: 234-263.

Lim TK. 2011. Durio zibethinus. In: Lim TK (ed.) Edible Medicinal and Non-Medicinal Plants. Springer, Singapore.

Lim TK, Luders L. 1998. Durian flowering, pollination, and incompatibility studies. Ann Appl Biol 132:151-165.

Low SL, Wong SY, Boyce PC. 2018. Naming the chaos: generic redelimitation in Schismatoglottideae (Araceae). Webbia 73: S1 S100.

Maas S, Karp DS, Bumrungsri S, Darras K, Gonthier D, Huang JCC, Lindell CA, Maine JJ, Mestre L, Michel NL, Morrison EB, Perfecto I Philpott SM, Sekercioğlu CH, Silva RM, Taylor PJ, Tscharntke T, Van Bael SA, Whelan CJ, Williams-Guillén K. 2016. Bird and bat predation services in tropical forests and agroforestry landscapes. Biol Rev 91: 1081-1101.

Masrol S, Ibrahim M, Adnan S. 2015. Chemi-mechanical pulping of Durian rinds. Procedia Manuf 2: 171-180.

Matius P, Tjwa SJM, Raharja M, Sapruddin, Noor S, Ruslim Y. 2018 Plant diversity in traditional fruit gardens (munaans) of Benuaq and Tunjung Dayaks tribes of West Kutai, East Kalimantan, Indonesia. Biodiversitas 19: 1280-1288.

Momose K, Yumoto T, Nagamitsu T, Kato M, Nagamasu H, Sakai S, Harrison R, Itioka T, Hamid A, Inoue T. 1998. Pollination biology in a lowland dipterocarp forest in Sarawak, Malaysia. I. Characteristics of the plant-pollinator community in a lowland dipterocarp forest. Am J Bot 85: 1477-1501.

Nyffeler R, Baum DA. 2000. Phylogenetic relationships of the durians (Bombacaceae-Durioneae or /Malvaceae/Helicteroideae/Durioneae) based on chloroplast and nuclear ribosomal DNA sequences. Plant Syst Evol 224: 55-82.

Nyffeler R, Baum DA. 2000. Systematics and character evolution in Durio s. lat. (Malvaceae/Helicteroideae/Durioneae or Bombacaceae Durioneae). Org Divers Evol 1: 165-178.
POWO 2019. Plants of the World Online. Facilitated by the Royal Botanic Gardens, Kew. http://www.plantsoftheworldonline.org/taxon/urn:lsid:ipni.org:names: 25 864-1\#children

Salma I. 2011. Durio of Malaysia. Malaysian Agricultural Research and Development Institute, Kuala Lumpur.

Santoso PJ. 2010. Lai, colored durian, attractive flesh: the potential for export. Iptek Horti 6: 36-41. [Indonesian]

Sheema A, Clements G, McConkey K, et al. 2017. Pollination by the locally endangered island flying fox (Pteropus hypomelanus) enhances fruit production of the economically important durian (Durio zibethinus). Ecol Evol 7: 8670-8684.

Sheherazade, Ober HK, Tsang SM. 2020. Contributions of bats to the local economy through durian pollination in Sulawesi, Indonesia. Biotropica 52: 577-586.

Srianta I, Hendrawan B, Kusumawati N, Blanc PJ. 2012. Study on durian seed as a new substrate for angkak production. Intl Food Res 19: 941945.

Sritongchuay T, Bumrungsri S. 2016. Specialized and facultative nectarfeeding bats have different effects on pollination networks in mixed fruit orchards, in Southern Thailand. J Pollinat Ecol 19: 98-103.

Sritongchuay T, Kremen C, Bumrungsri S. 2016. Effects of forest and cave proximity on fruit set of tree crops in tropical orchards in Southern Thailand. J Trop Ecol 32: 269-279

Sritongchuay T, Hughes AC, Bumrungsri S. 2019. The role of bats in pollination networks is influenced by landscape structure. Glob Ecol Conserv 20: e00702. DOI: 10.1016/j.gecco.2019.e00702.

Soepadmo E, Eow BK. 1977. The reproductive biology of Durio zibethinus Murr. Gard Bull Sing 19: 25-33.

Stevens PF. 2001 onwards. Angiosperm Phylogeny Website. Version 14, July 2017 [and more or less continuously updated since]. http://www.mobot.org/MOBOT/research/APweb/.

Stewart AB, Dudash MR. 2016. Field evidence of strong differential pollen placement by Old World bat-pollinated plants. Ann Bot 119: 73-79.

Suwanseree V, Yapwattanaphun C. 2017. Climates variables affect flowering and harvest times of durian, mangosteen and banana in eastern Thailand. Acta Hortic 1186: 109-114.

Syahruddin K. 2012. Genetic diversity of durian (Durio zibethinus Murr.) using morphological and molecular (ISSR) markers. [Thesis]. Institut Pertanian Bogor, Bogor. [Indonesian]

Tang KHD. 2019. Climate change in Malaysia: Trends, contributors, impacts, mitigation and adaptations. Sci Total Environ 650: 18581871.

Thavry H., Cappelle J, Bumrungsri S, Thona L, Furey NM. 2017. The diet of the cave nectar bat (Eonycteris spelaea Dobson) suggests it pollinates economically and ecologically significant plants in Southern Cambodia. Zool Stud 56: e17.

Tirtawinata M, Mulyanto E. 2017. The discovery of new red durians in Indonesia. Acta Hortic 1186: 29-34.

Tsang SM, Wiantoro S. 2019. Review - Indonesian flying foxes: research and conservation status update. Treubia 46: 103-113.

Wayo K, Phankaew C, Stewart AB, Bumrungsri S. 2018. Bees are supplementary pollinators of self-compatible chiropterophilous durian. J Trop Ecol 34: 41-52.

Winarni B, Lahjie AM, Simarangkir BDAS, Yusuf S, Ruslim Y. (2017) Tengkawang cultivation model in community forest using agroforestry systems in West Kalimantan, Indonesia. Biodiversitas. 18 (2): 765-772.

Yumoto T. 2000. Bird-pollination of three Durio species (Bombacaceae) in a tropical rainforest in Sarawak, Malaysia. Am J Bot 87: 11811188.

Zapata TR, Aroyo MTK. 1978. Plant Reproductive Ecology of a Secondary Deciduous Tropical Forest in Venezuela. Biotropica 10: 221-230. 